\title{
Personality and Psychopathology: A Stagnant Field in Need of Development
}

\author{
C. EMILY DURBIN ${ }^{1 *}$ and BRIAN M. HICKS ${ }^{2 *}$ \\ ${ }^{1}$ Michigan State University, East Lansing, MI, USA \\ ${ }^{2}$ University of Michigan, Ann Arbor, MI, USA
}

\begin{abstract}
A dominant paradigm in psychopathology research proposes that individual differences in personality are centrally involved in the origins and manifestations of psychopathology, and structural models of personality and psychopathology have been extremely useful in helping to organize associations among many traits and disorders. However, these models merely describe patterns of covariation; they do not explain the processes by which these patterns emerge. We argue that the field is stagnated, as it is overly focused on the demonstration of concurrent associations and on confirming a spectrum model that proposes traits and disorders are manifestations of the same underlying constructs. We contend that if the field is to move towards an understanding of causal processes, it must integrate knowledge and principles of personality development and developmental psychopathology. To begin this integration, we review (i) normative trends in personality change, (ii) age-related changes in the prevalence of disorders, and (iii) the impact of onset and chronicity on the severity of disorders. We propose several developmental processes that may contribute to the co-development of personality and psychopathology. We then present novel empirical findings to illustrate how a developmental perspective on traits and disorders can inform new hypotheses and propose principles and hypotheses that should guide future research. Copyright (C) 2014 European Association of Personality Psychology
\end{abstract}

Key words: personality; psychopathology; depression; substance abuse; development

\section{INTRODUCTION}

Personality science has made fundamental contributions to theories and research approaches in the study of psychopathology. Advances in basic personality research brought much needed clarity to efforts to organize individual differences variables relevant to psychopathology, identifying coherent patterns of emotional, motivational, and cognitive processes that relate to constructs central to many disorders. Personality research has highlighted the utility of studying normal populations and of placing individual differences within their developmental context to explore the etiology of psychopathological processes. Despite this venerable tradition, much of the current research at the intersection of personality and psychopathology is stuck in the correlate stage, that is, in simply demonstrating associations between disorders and personality traits. Although there are several recent examples that transcend this, papers of this correlational kind continue to accumulate, creating a hazard that the field will stagnate or arrive at premature or simplistic conclusions regarding the nature of trait-disorder associations.

We highlight characteristics of contemporary research on the relations between personality traits and psychopathological conditions that we see as emblematic of these problems and identify important findings and paradigms from modern

*Correspondence to: C. Emily Durbin, Department of Psychology, Michigan State University, Psychology Building, 316 Physics Road, East Lansing, MI 48824, USA. E-mail: cdurbin@msu.edu

Brian M. Hicks, Department of Psychiatry, University of Michigan, 4250 Plymouth Rd, Ann Arbor, MI 48109, USA. E-mail: brianhic@umich.edu personality science and developmental psychopathology that we believe have the potential to reinvigorate this domain. In our view, the most fruitful way forward involves retaining critical conceptual distinctions between the domains of personality and psychopathology to facilitate more precise hypotheses regarding mechanisms that account for their interrelation. To do so, we describe how personality traits and mental disorders have similar developmental trajectories that may reflect common processes, and how individuals with disorders exhibit personality change that deviates from these prototypical patterns. We also discuss how personality-environment transactions that occur in the context of changing developmental pressures are critical for understanding individual differences in these patterns of trait and disorder change.

Our aim is to provoke discussions that will advance theory and empirical study that integrates the personality and psychopathology literatures. Specifically, we believe that personality science has made important strides in describing and explaining developmental changes in personality constructs, and that psychopathology research can benefit from consideration of these developmental patterns and their implications for trajectories of maladjustment across the lifespan. In parallel fashion, findings from psychopathology research can broaden our understanding of personality development, the study of which has primarily focused on positive aspects of development, such as maturation and adaptation. However, as the prevalence of common disorders demonstrates, many people struggle with maturation and adaptation, some for brief periods and others for much of their lifetimes. Understanding these common, but 
problematic, outcomes and patterns and their interrelationships with personality constructs will enrich our understanding of personality development.

To illustrate these issues more concretely, we focus on empirical findings and theoretical models of personalitypsychopathology associations for two common forms of psychopathology: major depressive disorder (MDD) and alcohol use disorder (AUD). We first describe and evaluate conceptual models of the nature of associations between these disorders and personality traits and discuss issues that arise in testing these models. Second, we discuss general principles and specific hypotheses that are suggested by a developmental psychopathology approach and knowledge of normative personality development. We highlight the critical roles of two developmental parameters of psychopathology, age of onset and chronicity, as examples of how a developmental perspective is informative for understanding associations between personality traits and disorders. Third, we present novel empirical findings using data from a large longitudinal study to illustrate the impact of these developmental parameters on the associations between personality and MDD and AUD from childhood through young adulthood. Finally, we recommend avenues for future research.

\section{Structures of personality and psychopathology domains}

We focus our review on trait models of personality, the dominant paradigm in the personality-psychopathology literature. This paradigm defines personality as dimensions of individual differences in affect, behaviour, and cognition that are relatively stable across time and situations and can be hierarchically organized from relatively narrow constructs at lower levels to broad constructs at higher levels. There is a general consensus that the highest levels of the hierarchy are best organized around three to five broad dispositions, with the lower order traits being narrower constructs with links to the broad dispositions. The 'Big Five' models represent attempts to understand the organization of the natural language of trait descriptions and include the traits of neuroticism, extraversion, conscientiousness, agreeableness, and openness to experience (Goldberg, 1990; John \& Srivastava, 1990). The 'Big Three' model emerged from factor analytic studies focused on understanding the structure of theoretically derived trait constructs and includes negative emotionality (NE), positive emotionality (PE), and constraint $(\mathrm{CN})$ versus disinhibition (Eysenck \& Eysenck, 1985; Tellegen, 1985).

There is substantial overlap between the Big Three and Big Five models such that they capture most of the same variance, with some differences in organization (Church, 1994; Clark \& Watson, 1999). Extraversion and neuroticism are essentially equivalent to $\mathrm{PE}$ and $\mathrm{NE}$, respectively, although the Big Three constructs are broader than those of the Big Five. NE incorporates aspects of low agreeableness (e.g. aggression and suspiciousness), and PE includes elements of conscientiousness (e.g. achievement striving). $\mathrm{CN}$ is a mix of the remaining components of conscientiousness and agreeableness (e.g. self-control versus impulsivity, harm avoidance versus thrill seeking, and conformity versus rebelliousness). Openness to experience has small to medium associations with elements of PE and CN but is largely independent of the Big Three, focusing on willingness to explore one's culture.

In contrast to this dimensional conception of personality, mental disorders have historically been conceptualized as categorical and relatively distinct from one another. A growing consensus, however, rejects this system, proposing that patterns of co-occurrence between putatively distinct disorders point to a coherent clustering of disorders on the basis of common symptom features that can be organized using a relatively simple structure. Most structural analyses of psychopathologies have focused on common mental disorders (those with prevalence rates $>1 \%$ ) and have consistently identified two correlated but distinct factors: an internalizing factor emerging from the high rates of co-occurrence among depressive and anxiety disorders, and an externalizing factor reflecting high comorbidity among substance use disorders and antisocial behaviour (Kendler, Prescott, Myers, \& Neale, 2003; Krueger, 1999; Vollebergh et al., 2001).

These findings are typically interpreted as indicating the presence of two spectra, each consisting of different forms of dysfunction of which 'distinct' disorders within that spectrum are alternative manifestations of a common psychopathological process. This common process is viewed as dimensional in nature, such that someone with a high liability on internalizing (or externalizing) is likely to meet criteria for multiple disorders within that spectrum. The structure and conceptualization of psychopathology thus resemble that of personality, with internalizing and externalizing at the top of a hierarchy as broad liabilities, and individual disorders at lower levels of the hierarchy representing more specific manifestations of those broad liabilities (Eaton et al., 2013; Hicks, Krueger, Iacono, McGue, \& Patrick, 2004; Krueger et al., 2002; Krueger, Markon, Patrick, Benning, \& Kramer, 2007).

\section{Cross-sectional associations between personality and psychopathology constructs}

The literature on associations between personality and psychopathology is voluminous, and the hierarchical structural models discussed earlier provide substantial utility in efficiently organizing and summarizing these findings. NE/ neuroticism characterizes nearly all disorders, but externalizing has also been linked with low CN (Krueger, McGue, \& Iacono, 2001). These traits are associated in similar ways to specific disorders within each spectrum, although there are also some notable specific disorder-trait associations. For example, prominent theories of internalizing posit specific associations between depressive disorders and low PE (Clark \& Watson, 1991; Mineka, Watson, \& Clark, 1998). This general pattern of associations was supported by an extensive meta-analysis of 175 studies (Kotov, Gamez, Schmidt, \& Watson, 2010) that demonstrated large associations between neuroticism and all internalizing and externalizing disorders, and specific large associations between extraversion and internalizing. Importantly, conscientiousness had a large and nonspecific association with internalizing and externalizing disorders, which was somewhat surprising given its lower prominence in theoretical models of psychopathology. 
Further insights are offered by examining lower levels of the trait hierarchy. Krueger, Caspi, Moffitt, Silva, and McGee (1996) examined trait profiles of four disorder groups (antisocial behaviour, depressive, anxiety, and substance use disorders) on 10 lower order scales of a Big Three measure, the Multidimensional Personality Questionnaire (MPQ; Tellegen \& Waller, 2008) in a populationrepresentative sample. They explored comorbidity by comparing two definitions of disorder: 'pure' cases meeting criteria for only one diagnostic class, and all cases with the disorder regardless of whether they also met criteria for other disorders. Both groups were compared with a diagnosisfree control group. Several important findings emerged. First, the depressive and anxiety disorder groups exhibited similar personality profiles, whereas the substance use disorder and antisocial behaviour groups had similar profiles. This was consistent with conceptualizations of internalizing and externalizing spectra as having distinctive patterns of associations with traits. Second, although all disorder groups were high on NE, they differed in their specific lower order trait elevations within NE. Those with depressive and anxiety disorders were most elevated on stress reaction, and those with substance use disorders and antisocial behaviour on aggression. Third, substance use disorders and antisocial behaviour had specific associations with low $\mathrm{CN}$. Fourth, all disorder groups were low on the communal facets of PE (social closeness and well-being). Fifth, personality elevations were less extreme for the pure diagnostic groups relative to groups that included persons with comorbid disorders, suggesting a strong association between the extent of disorder and degree of personality deviation.

\section{Limits to structural models and correlational associations}

Structural models are a fundamental first step in providing an organizational scheme for establishing that individual differences in traits overlap with disorders in predictable ways. Their findings imply associations that need to be explained and provide linkages to a broader literature on normal personality that can inform understanding of individual differences in psychopathology. Important design issues have led some to overstate the findings of these studies in ways that we believe have stagnated the field's empirical and theoretical growth. For example, cross-sectional designs in which traits and disorders are assessed using the same method yield effect sizes that are inflated by shared method variance that may then spuriously support some models of trait-disorder associations (i.e. the spectrum model, described subsequently). Furthermore, analyses of concurrent associations are not informative about how the associations were established. We argue that in order to generate new knowledge, it is important to retain conceptual distinctions between traits and disorders. This is critical for answering questions such as why some persons with elevated NE exhibit the unique symptoms of depression that are distinct from NE while others do not, and how these processes are similar to or distinct from those that result in depressive symptoms among people who are not high in NE. Such knowledge will not result from structural analyses but from different designs and approaches that focus on illuminating processes, rather than patterns of covariance. As far back as 1995, in their important review of links between depressive disorders and traits, Watson and Clark (1995) stated

clearly, we no longer need studies to determine whether temperament and depression are related ... the real need is for studies that help to clarify how and why temperament is related to depression and other forms of psychopathology (p. 363).

Structural models of personality-psychopathology associations rely on latent variable models of personality traits as both organizational and explanatory constructs. The assumptions of this approach were the focus of a recent critique of personality models by Cramer et al. (2012). They proposed a network model that reframes personality dimensions as co-occurring behavioural dispositions that emerge from direct causal relationships between individual behaviours, rather than from a single latent trait process. They proposed that trait-disorder associations be disaggregated into specific causal links among components of the two systems (e.g. the effect of feeling nervous around others lowers the frequency of social contact, which produces the depressive symptom of anhedonia). Rather than latent variable approaches to modelling trait-disorder covariance, this approach uses network analysis to identify stronger versus weaker associations between the lowest-level indicators of personality (items) and disorders (symptoms). This model is useful and provocative in that it encourages a focus on narrower mechanisms that cause correlations among trait and disorder measures (without articulating what those mechanisms might be or why they may differ across persons) and forces researchers to think more clearly about the conceptual limitations of latent variable models of personality. However, we believe this approach lacks a broader connection to lifespan developmental processes, which is crucial for understanding how and under what circumstances traits and disorders are causally connected.

\section{Models of personality-psychopathology associations}

Most studies exploring associations between personality and psychopathology frame their findings with respect to one or more of an influential list of theoretical models, first articulated as a set 20 years ago to describe potential causes of overlap between personality and depressive disorders (Klein, Wonderlich, \& Shea, 1993; Watson \& Clark, 1995). They include the following: spectrum, precursor, predisposition, common cause, concomitants, scar, and pathoplasty. Subsequently, we describe these models and their predictions, evaluate their abilities to support critical empirical tests and discuss misfit between their assumptions and recent findings regarding personality development. Finally, we propose an alternative, developmentally informed framework for future investigations.

The spectrum or continuity model eliminates all conceptual distinctions between the trait and disorder in question, viewing them as describing the same phenomena. Symptoms lie on the extreme end of the same dimension as the trait; 
extreme trait levels shade continuously into (and in some cases, overlap with) symptoms. Behaviours, cognitions, and motivations that define the trait and those that are characterized as symptoms are presumed to be caused by individual differences in the same underlying psychological dimension. This view contrasts with the Cramer et al. (2012) network model of personality, under which, rather than being indistinguishable, some phenomena are actually more central to particular traits by virtue of their stronger interconnections to other expressions of the trait.

There are several important implications of the spectrum model. First, measures of the trait and of the disorder should be strongly associated, as they are measuring the same construct. This is the prediction most commonly cited in the literature as providing evidence for the spectrum model (Clark, 2005; Krueger \& Tackett, 2003; Mervielde, De Clerq, De Fruyt, \& Van Leeuwen, 2005), with many taking findings of significant associations between a trait and disorder as de facto confirmation of the spectrum model. However, if one accepts statistically significant or even moderately sized associations as evidence for this model, it becomes barely falsifiable, particularly when tested in cross-sectional designs employing self-report questionnaire assessment of both constructs. In the strongest version of this model, the magnitudes of the associations should be quite large (e.g. approaching the reliabilities of the measures) as they are tapping the same underlying dimension. The second implication of the spectrum model is that all individuals with a particular disorder should also have extreme levels of the trait(s), and conversely, all those with extreme trait scores should have one or more of the disorders linked to that trait. Third, measures of the trait and the disorder should have very similar patterns of external correlates, as they mark the same dimension. We are aware of no studies that have directly tested either of these two predictions of the model. Fourth, the factors that give rise to individual differences in the trait are the same as those that cause the disorder. Finally, as noted by Klein, Kotov, and Bufferd (2011), the spectrum model presumes a fairly specific association between the trait and disorder; if a trait is equivalently associated with different disorders known to reflect at least somewhat distinct processes, then it is difficult to conclude that the trait is the same thing as each of these different disorders. This is particularly relevant for neuroticism and conscientiousness, as each has ubiquitous associations with both internalizing and substance use disorders. This lack of specificity disconfirms the spectrum hypothesis for these traits (Ormel et al., 2013), a point often overlooked by proponents of the spectrum model. Rather, these nonspecific associations may indicate that some elements of high neuroticism and low conscientiousness are outcomes of disorders, reflecting the dysphoria and failures of self-regulation that may emerge as results of other pathological processes more central to the disorders (Ormel et al., 2013).

Under the precursor/prodrome model, expressions of a trait represent early points along the trajectory towards the disorder; the phenomenology of the trait is a weaker or incipient version of the disorder's symptoms. Both the precursor and spectrum model imply that the disorder represents a more severe variant of an underlying phenomenon. However, the precursor model adds a developmental proposition, namely that a person must 'pass through' a period of exhibiting extreme trait levels prior to expressing symptoms. One finding consistent with the precursor model is when high trait levels predict more rapid onset of symptoms (Fanous, Neale, Aggen, \& Kendler, 2007). In contrast to the spectrum model, the precursor model implies that the trait and disorder do not occupy entirely overlapping conceptual or etiological spaces, as some additional factors must be invoked to explain why some people with relevantly extreme levels of the trait go on to manifest the disorder, whereas others do not.

The common cause model is distinguished from the prior two models in that it specifies disorders and traits are distinct. Their interrelationship emerges from the fact that they share at least some of their causal factors. Under the strongest version of this model, the two constructs do not have any direct causal relationship with one another after accounting for their shared etiology. Presumably, these shared etiological factors also account for any overlap in their external correlates. The common cause model is consistent with evidence for overlapping genetic contributions to NE and depression (Kendler, Gatz, Gardner, \& Pedersen, 2006) and externalizing disorders and low CN (Krueger et al., 2002; Slutske et al., 2002), although these data are also consistent with many of the other theoretical models, as well.

The predisposition, pathoplasty, concomitants, and scar models all suggest causal relationships between distinct traits and disorders. Under the predisposition model, individual differences in the trait (which emerge from one set of processes) increase risk for the disorder via a separate set of processes, and trait-relevant processes are only one source among many processes potentially etiologically implicated in the disorder. The trait and the disorder need not share any surface phenomenological features (unlike in the spectrum model). Central to this model is the proposition that trait-disorder links are causal; thus, to test it, at minimum a prospective design should be employed, ideally one with study elements that support causal inferences, such as the use of genetically informative designs or experimental manipulations of predisposing processes.

In the pathoplasty or exacerbation model, the trait does not operate directly to cause the disorder; however, once the disorder has developed, the trait influences presentation or course (the pattern or severity of symptoms, course, or treatment response). For example, NE predicts poorer course and treatment response among those with depression (Quilty et al., 2008; Tang et al., 2009). However, such evidence alone is hardly conclusive. Traits may predict treatment response or another outcome not because they shape disorder post-onset but because those with more severe variants of the disorder had more extreme pre-existing trait levels, as proposed under all the other models described so far.

Under the concomitants or state model, associations between traits and disorders are confounds of measurement or temporary artefacts of the impacts of symptoms on trait-relevant behaviours. For example, acute depression is associated with more negative self-perceptions that may bias self-reports of negatively evaluative traits. In fact, withinsubjects analyses show that NE is elevated when people are 
depressed compared with when they are not (Kendler, Neale, Kessler, Heath, \& Eaves, 1993; Ormel et al., 2004).

The scar/complication model proposes that the occurrence of a disorder changes one's personality such that traits are altered by the experience of the disorder and are thus different after the disorder onsets (compared with the pre-morbid trait level) and remain in their changed state even after the disorder remits. For example, one study found evidence of a scar effect, such that MDD predicted higher NE at a later time point, controlling for NE at an earlier time point (Fanous et al., 2007; Kendler et al., 1993). However, three other studies have failed to find scar effects of MDD on NE (Duggan, Sham, Lee, \& Murray, 1991; Ormel et al., 2004; Zeiss \& Lewinsohn, 1988).

These models describe relatively idealized conceptions of why personality traits and disorders are linked that are useful to the extent they generate testable predictions. In our view, these models are no longer stimulating growth in this way. The typical research design and findings published today differ little from those that characterized the literature 20 years ago when the models were first proposed, and there is no consensus that any one of these models has been disconfirmed or any one has been uniquely supported.

Several factors likely contributed to this stagnation. First, many of the models make similar predictions, making it difficult to conduct critical tests providing evidence for one model and against another. See Table 1 for a summary of these predictions, and note that most unique predictions require more challenging research designs seldom seen in the literature. Second, the models are often imprecise; for example, the spectrum model does not specify how symptoms that appear only at certain times reflect the same phenomenon as trait expressions that typically are viewed as relatively stable. Third, different models refer to processes that are not mutually exclusive but could co-occur within individuals and may be more relevant for some persons than for others. Finally, and perhaps most importantly, these models do not adequately integrate a modern understanding of personality development in which traits are viewed as dynamic constructs. The existence of normative lifespan changes in traits complicates the interpretation of data relevant to several predictions of these models. For example, if a trait is a precursor for depression but mean levels of that trait increase in the population during particular developmental intervals, should we expect greater population vulnerability during those intervals? Or, would risk be limited to those who had elevated levels at an earlier period?

\section{Developmental psychopathology as an alternative approach}

As an alternative, we propose an approach informed by developmental psychopathology, which conceptualizes psychopathology as deviation from normative development (Cicchetti, 1993), as a more fruitful means of understanding trait-disorder associations. This framework emphasizes the importance of understanding normative developmental processes that produce age-related changes in mean levels of traits and in prevalence rates of disorders. Incorporating normative trends grounds an approach to identifying and characterizing abnormal processes, guided by the principles of co-development of traits and disorders. By co-development, we refer to the following principles: (i) traits and disorders are dynamic rather than static in nature, such that they are responsive to the actions of other forces, including developmental pressures that may cause them to change in similar ways; (ii) downstream effects of traits and disorders on functioning may constrain or provide affordances for change in the other domain, such that they become causally intertwined; and (iii) both traits and disorders unfold in the broader context of lifespan development, namely tasks, goals, and relationships that emerge and shift in importance to the person over time (Baltes, 1987; Masten et al., 1995, 2004; Roisman, Masten, Coatsworth, \& Tellegen, 2004). Individual differences in adaptation central to both psychopathology and personality are reflected in the ways in which people navigate these life changes. For this reason, we propose that the processes that link traits and disorders may vary across different developmental periods or for persons whose experiences of these periods are characterized by different needs, goals, or challenges.

One simple heuristic for concretizing these co-development principles is to utilize basic data on normative change to identify individuals whose developmental trajectories are non-normative. For example, those who fail to exhibit personality change similar to the majority of their peers and those with disorders whose courses are unusual relative to others with the same conditions (e.g., an early onset) are particularly informative. Study designs that include multiple assessments of both traits and disorders during key developmental periods when significant normative change occurs are essential, and those that measure personality prior to disorder onset provide additional power for disconfirming causal hypotheses.

We discuss the initial steps to conducting such research and provide some illustrative data for two common forms of internalizing (MDD) and externalizing (AUD) psychopathology. First, we summarize the empirical literature on normative developmental trends for personality traits and prevalence rates for MDD and AUD. Second, we highlight some developmentally informed predictions derived from these literatures. Third, we provide specific examples of the utility of this framework by discussing findings from a large longitudinal study of the associations between these disorders and personality over the crucial developmental period from pre-adolescence through young adulthood.

\section{Normative trends in personality change}

There is now resounding evidence that (i) personality is one of the most stable psychological characteristics, and (ii) reliable changes in mean levels of traits are evident, especially during specific developmental periods. These two findings can be reconciled by acknowledging that they refer to different types of change potentially influenced by distinct processes. Findings for stability emerge from explorations of differential change or rank-order stability, as indexed by test-retest correlations. Findings demonstrating significant changes in traits reflect absolute change, as indexed by differences in scores between time points (mean-level or normative change, when assessed in a cohort). 


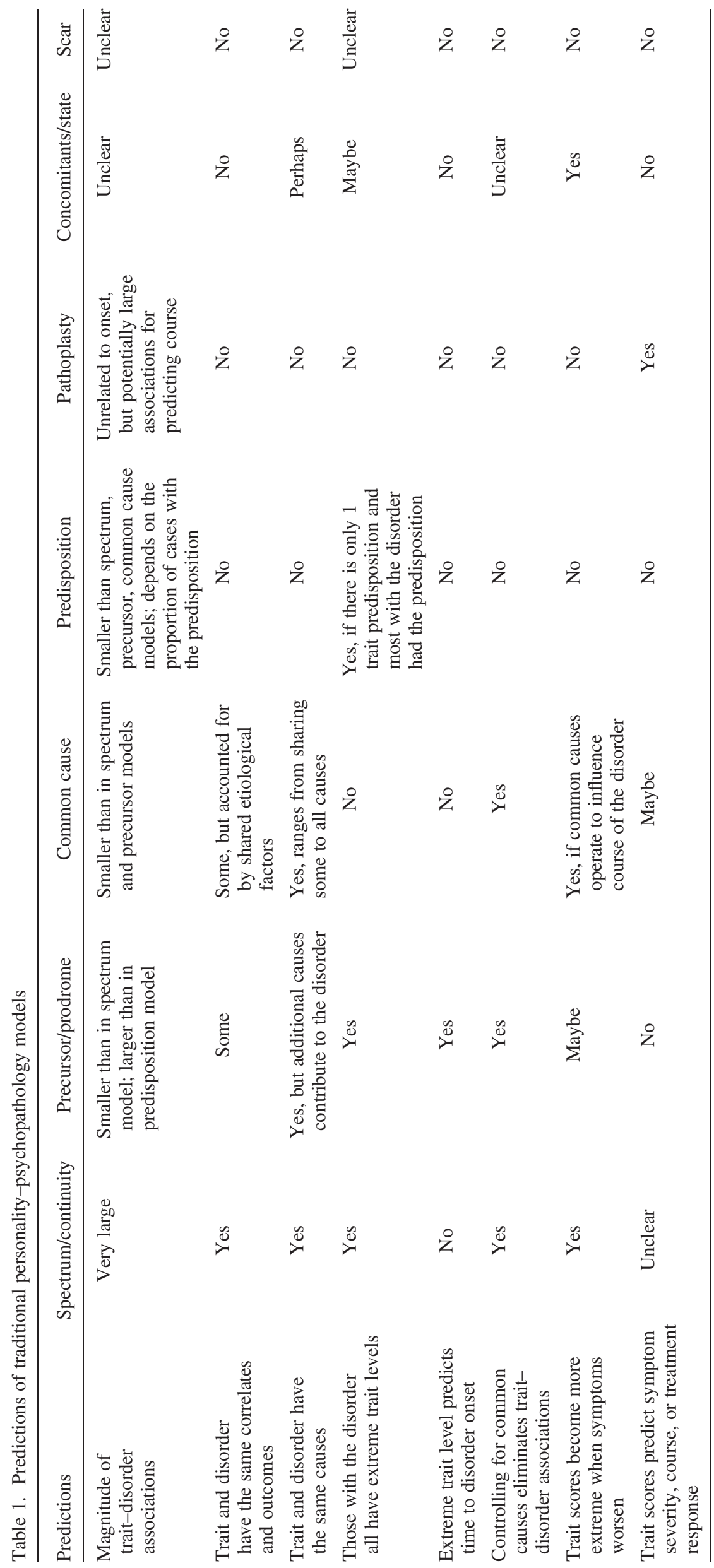


Roberts et al. (2000, 2006) conducted two large metaanalyses summarizing findings regarding stability of personality traits. Roberts and DelVecchio (2000) found that rank-order stability coefficients for Big Five traits were moderate in magnitude throughout the life course and increased with age, from .30 in childhood to .55 by age 30 years, reaching a plateau of .70 between ages 50 and 70 years. Several other findings were noteworthy. First, stability coefficients tended to decrease as the time interval between assessments increased. Second, there was little variation in stability across traits. Third, although significant change was evident, personality traits are more stable than most other psychological characteristics, with the notable exception of general cognitive ability. Finally, moderate but substantial rank-order stability was observed relatively early in life and steadily increased despite the accumulation of major life changes characteristic of some developmental periods that might be expected to alter trait trajectories.

Regarding absolute change, Roberts, Walton, and Viechtbauer (2006) uncovered a complex picture for Big Five traits. This was especially the case for extraversion, as it had to be disaggregated into facets of social dominance (agentic PE) and social vitality (communal PE) to fully capture mean-level changes. Social dominance increased from adolescence through early middle age ( $d=1.07$ from ages $10-40$ years), whereas social vitality increased in adolescence $(d=0.17$ from ages 10 to 22 years) and then decreased in young adulthood ( $d=-0.16$ from ages 22 to 30 years) and old age $(d=-0.16$ from ages 60 to 70 years). Agreeableness increased in young adulthood ( $d=0.17$ from ages 22 to 30 years) and middle age ( $d=0.30$ from ages 50 to 60 years), whereas conscientiousness increased steadily throughout adulthood $(d=0.86$ from ages 22 to 70 years). Neuroticism decreased steadily until about age 40 years $(d=-0.77$ from ages $10-40$ years) and was stable thereafter. Openness to experience increased in adolescence and young adulthood and decreased in old age.

Three findings are particularly important for understanding how traits might be associated with disorders. Most obviously, the existence of developmental change in mean levels of self-reported traits means that dynamic models of causal associations between traits and disorders can be tested, as within-person trait variation is a plausible candidate for influencing within-person change in onset, maintenance, and recovery from disorders. Alternatively, traits and disorders may covary over time because both are reacting to the same developmental influences. Rather than complicating notions of trait-disorder relationships, changes in traits open avenues for exploring the causes of their interrelationships.

Several aspects of developmental change in traits are particularly relevant. First, rank-order stability is lowest in childhood, suggesting that trait-disorder associations observed at the earliest ages may differ from those observed at later periods. Traits that correlate with a particular disorder in children may not be the same traits that correlate with that disorder among adults because functional correlates of traits may vary in the context of different developmental pressures. Similarly, in longitudinal data, a childhood trait that predicts a disorder in adulthood (i.e., a predisposition) may not exhibit a cross-sectional association with that disorder in either childhood or adulthood. Second, the greatest mean level changes in the population are observed during late adolescence through emerging adulthood (approximately ages 18-25 years; Arnett, 2000). If disorders and traits share common causes, then this period may also be one in which causes of common psychopathologies are changing in prevalence or impact. Third, this transition is characterized chiefly by decreases in $\mathrm{NE}$ traits and increases in $\mathrm{CN}$ traits. This normative trend towards greater emotional stability and behavioural control has been dubbed the maturity principle (Caspi, Roberts, \& Shiner, 2005). Theories seeking to account for these changes may also shed light on the etiology of trait-disorder co-development.

\section{Theories accounting for normative personality change and individual differences in change}

The large changes observed during the transition into adulthood can be conceptualized to result from a developmental 'press'. Salient developmental tasks of this period, many of which reflect evolutionarily relevant goals (Denissen, van Aken, \& Roberts, 2011) such as achieving an independent financial and living situation, obtaining stable employment, and establishing an intimate partner relationship and family (Masten et al., 2004; Roisman et al., 2004), are more complex and carry with them greater expectations for individual responsibility, relative to those of adolescence and childhood. The term competence has been used to describe success in performing these tasks within the guidelines of a given sociocultural context (Masten et al., 1995, 2004).

One hypothesis is that to adapt successfully, individuals must attain greater levels of psychological maturity, and we have elsewhere argued that relatively competent individuals typically exhibit personality profiles similar to the trait definition of maturity, that is, low $\mathrm{NE}$ and high $\mathrm{CN}$ relative to appropriate age-related norms (Hicks, Durbin, Blonigen, Iacono, \& McGue, 2012; Johnson, Hicks, McGue, \& Iacono, 2007). Thus, meanlevel trait maturation is a manifestation of psychological processes occurring in response to developmental pressures that enable adaptive outcomes. Relative immaturity in the early stages of these pressures may be normative precursors to ultimate maturation, as the new behaviours and cognitions required for success in these tasks take time to develop (Denissen, van Aken, Penke, \& Wood, 2013). This may initially decrease self-perceived competence. Consistent with this, there is some evidence that self-esteem exhibits a non-linear pattern of change with increases in early adolescence and later adolescence/early adulthood being offset by decreases in middle adolescence (Baldwin \& Hoffman, 2002). However, there are also significant individual differences in self-esteem trajectories across adolescence (Birkeland, Melkevik, Holson, \& Wold, 2012; Donnellan, Conger, \& Burzette, 2007) that may reflect individual differences in perceived competence in addressing developmental tasks (Huang, 2010).

There is substantial individual variability in the rates and magnitudes of personality change during this developmental period that is partly dependent upon initial personality structure. Individuals who exhibit significant changes on the most traits during the transition into adulthood tend to have the 
highest NE and lowest CN scores in adolescence (Blonigen, Carlson, Hicks, Krueger, \& Iacono, 2008; Donnellan et al., 2007; Roberts, Caspi, \& Moffitt, 2001). Conversely, individuals with the lowest $\mathrm{NE}$ and highest $\mathrm{CN}$ scores in adolescence tend to exhibit the fewest significant changes. This is not to say that adolescents low in $\mathrm{NE}$ and high in $\mathrm{CN}$ are sufficiently mature to take on adult responsibilities. Rather, at the time they encounter these challenges, they are better prepared to navigate them as some of the necessary behaviours, skills, and attitudes are already in their personality repertoires, rather than needing to come online de novo or in opposition to existing dispositional patterns that are inconsistent with new expectations. Consequently, these adolescents are likely to experience less uncertainty and greater self-efficacy about their ability to meet new demands, which might reduce their risk for psychopathology during this period. Less mature individuals, however, likely experience significant pressures to change and so have some 'catching-up' to do in terms of dispositional $\mathrm{NE}$ and $\mathrm{CN}$ if they are to successfully complete the tasks of adulthood. The processes by which such successful change does or does not occur are also subject to individual variation.

Population level mean changes provide a backdrop against which individual differences in developmental pathways are highlighted and their life functioning correlates made more salient (Denissen et al., 2011). Not everyone will exhibit the normative pattern of maturation during this period, and those who fail to mature or show changes away from the maturational trend would be expected to be at highest risk for maladjustment. Even those who do 'catchup' with their peers may still have lingering effects of their earlier trait levels. Johnson et al. (2007) examined trait change from age 14 to 24 years on 6 MPQ lower order scales, using growth mixture modelling to identify subgroups on the basis of initial levels and rate of change for each trait. Notably, although many of the groups with the most extreme scores on $\mathrm{NE}$ and $\mathrm{CN}$ traits at age 14 years moved towards greater maturity over time, these groups had the worst educational, occupational, relationship, and mental health outcomes at age 24 years. This was consistent with the fact that relative differences in trait levels were stable across most groups, such that the increases in $\mathrm{CN}$ and decreases in $\mathrm{NE}$ traits observed in the least mature group were not sufficient to close the gaps with their peers and achieve competent outcomes by young adulthood.

The rich theory generated by observations of trait change across the transition to adulthood suggests that focused examination of other developmental periods may reveal similar or unique developmental phenomena that potentially bear on the interrelationships of traits and disorders at other times in life. Other developmental periods may not be characterized by maturation. For example, a recent study that included multiple waves of personality data as measured by the MPQ from ages 11 to 30 years (Durbin et al., under review) found that the change towards maturity from late adolescence to adulthood was preceded by a period of change towards less maturity (increases in NE and decreases in $\mathrm{CN}$ ) from late childhood to late adolescence. These longitudinal findings replicate cross-sectional findings of decreasing trait maturity in early adolescence (Denissen et al., 2013; Soto, John, Gosling, \& Potter, 2011). Taken together, they implicate processes beyond the progressive maturation of traits, such as effects of life events (e.g. Specht, Egloff, \& Schmukle, 2011) or differential development of brain systems for reward and cognitive control (Steinberg, 2008), which might alter trajectories of trait change.

\section{Sex differences in personality trait change}

Another important finding from the personality development literature is the existence of sex differences in mean trait levels and their trajectories of change that have seldom been considered in the literature linking traits to psychopathology. In adulthood, meta-analyses (Feingold, 1994; Lynn \& Martin, 1997; Costa et al., 2001) reveal sex differences in neuroticism (higher in women), especially its anxiety/stress reaction components, and social potency facets of extraversion (higher in men). Similar effects have emerged in adolescent samples, with additional findings of higher aggression and lower in $\mathrm{CN}$ in boys (Blonigen et al., 2008; Donnellan et al., 2007; Roberts et al., 2001). Some of these differences are evident as early as childhood, including that for elevated fear/ stress reaction in girls and lower $\mathrm{CN}$ in boys (Else-Quest, Hyde, Goldsmith, \& Van Hulle, 2006; Olino, Durbin, Klein, Hayden, \& Dyson, 2013). Sex differences in trait change are more complex and inconsistent in the literature. There is evidence that some sex differences narrow and others widen during the transition from adolescence to adulthood (Blonigen et al., 2008; Donnellan et al., 2007; Roberts et al., 2001). Given sex differences in the prevalence of common disorders (Kessler et al., 2005), the existence of sex differences in personality development is an important phenomenon that should be incorporated into tests of the causes of trait-disorder associations. For example, if a trait and disorder are best characterized as lying on a spectrum, then sex differences in the two constructs should be equivalent. Sex differences in personality development may also point to the existence of different developmental pressures or adaptations to those pressures in males and females that might account for sex-differentiated risks for particular disorders at different developmental intervals (consistent with the common cause or predisposition models).

\section{Age-related trends in the prevalence of MDD and AUD}

Disorders also exhibit age-related (or 'normative') trends in typical age of onset, age periods of increase and peak in prevalence, and for some disorders, periods characterized by declines in prevalence. AUD exhibits a well-replicated pattern of typical age of onset and escalation of prevalence, as well as a period of decline in alcohol use and AUD symptoms (Bachman, Wadsoworth, O'Malley, Johnston, \& Schulenberg, 1997; Chassin, Flora, \& King, 2004; Chen \& Kandel, 1995; Hasin, Stinson, Ogburn, \& Grant, 2007; Johnston, O’Malley, \& Bachman, 1998; Johnstone, Leino, Ager, Ferrer, \& Fillmore, 1996). In the United States, a sizeable minority of adolescents (25-30\%) initiates alcohol use before age 15 years, a small subset of which also exhibit symptoms 
of AUD (Grant \& Dawson, 1997; McGue, Iacono, Legrand, Malone, \& Elkins, 2001). Steep increases in both heavy drinking and prevalence of AUD follow through adolescence and into young adulthood. By age 18 years, the lifetime prevalence of AUD is between $10 \%$ and $15 \%$ and continues to climb to roughly 25\% around ages 21-23 years (Hasin et al., 2007). Sharp declines in AUD prevalence and heavy drinking then begin around age 25 years, such that by age 30 years, the prevalence rates are nearly as low as those at age 18 years. There is then a slower but steady decline in prevalence for the rest of the life course, with an especially low rate of new onset cases after age 35 years (Verges et al., 2012). Patterns of quantity (and to a lesser extent frequency) of alcohol consumption also exhibit similar age-related trends even among people who never exhibit symptoms of AUD.

This pattern of decline during the third decade of life has been referred to as maturing out (Littlefield, Sher, \& Wood, 2009; Winick, 1962). Many have proposed it is the consequence of entering into adult roles that are incompatible with heavy drinking such as intimate partner relationships or marriage, parenthood, and commitment to work, key developmental tasks that define competence during this period of life (Bachman et al., 2002; Jessor, Donovan, \& Costa, 1991; Neyer \& Asendorpf, 2001; Yamaguchi \& Kandel, 1985). Thus, both declines in heavy drinking and maturation of $\mathrm{NE}$ and $\mathrm{CN}$ traits have been linked to similar developmental pressures of young adulthood. One interpretation of these findings is that $\mathrm{CN}$ and NE traits and AUD symptoms covary because of these shared pressures that act causally on both. Understanding the relationship between AUD and personality traits then must integrate these major mean-level shifts in both constructs from adolescence to young adulthood.

MDD does not have a normative developmental trajectory as pronounced as that for AUD, suggesting more heterogeneity in the role of developmental processes in depression. However, rates of depression increase substantially from childhood to adolescence (Kessler \& Wang, 2009), from low 12-month prevalences in preschool and childhood periods (2-5\%; Egger \& Angold, 2006; Rohde et al., 2013) to approximately $8 \%$ in adolescence (Birmaher et al., 1996; Costello, Erkanli, \& Angold, 2006; Lewinsohn, Clarke, Seeley, \& Rohde, 1994), a rate similar to that observed in adulthood. Although new onsets can occur at any point in the lifespan, risk of developing a first episode decreases with age; the majority who will ever meet criteria for MDD will have their first episode by young adulthood (Rohde, Lewinsohn, Klein, Seeley, \& Gau, 2013; Zisook et al., 2007). Most episodes that occur later in life are clustered among those with history of the disorder (thus, not new cases). There is no phenomenon analogous to 'maturing out' for depressive disorders in emerging adulthood as new onsets and recurrences are quite common during this period (Rohde et al., 2013). The differences in the pattern of prevalence rates across development for AUDs and depressive disorders, as well as the more variable developmental course for the latter, suggest that the particular developmental processes that may contribute to associations between traits and depressive disorders are not the same as those linking traits and AUD.
Sex differences in AUD and MDD trajectories correspond to those in the individual trait trajectories. Rates of AUD are very low and similar in boys and girls in middle adolescence (Hicks \& Zucker, 2014; Keyes, Grant, \& Hasin, 2008) then increase through late adolescence, with even sharper increases through the transition into adulthood. These increases, however, are steeper for boys and desistence (maturing out) occurs earlier for girls. By age 25 years, these gender differences in developmental trends produce a sex ratio for lifetime AUD prevalence of about 2.5:1 in favour of men (Hicks \& Zucker, 2014; Keyes et al., 2008). Thus, rates of AUDs change over development in men and women in ways similar to their overall mean levels and changes in traits such as $\mathrm{CN}$ and aggression.

The sex ratio of MDD prevalence in adults is also $2: 1$, but more cases are evident in women. However, this sex difference does not appear until mid-adolescence (Costello et al., 2006; Hankin \& Abramson, 2001), after which it does not change in magnitude across the remainder of the lifespan. Prior to mid-adolescence, boys actually have higher rates of depressive disorders than girls, although these differences are statistically significant in some studies (Angold, Costello, \& Worthman, 1998) and nonsignificant in others (Anderson, Williams, McGee, \& Silva, 1987). This observation is consistent with girls' higher mean levels of some aspects of NE and increases in this trait for girls (but not boys) in mid-adolescence (Durbin et al., under review), the period when girls first begin to outpace boys in onset of depressive disorders.

\section{What alternative models of personality-psychopathology associations are suggested by these normative trends?}

Descriptions of the nature and causes of normal personality development and data characterizing trajectories of disorders provide a broad framework for exploring a variety of developmentally informed hypotheses to explain trait-disorder associations. We believe the current literature suggests several principles and processes to inform future studies; they add more specificity to ideas conveyed by the traditional models described earlier (Table 1), rather than replacing them. Empirical studies based on these principles should help to disconfirm the predictions of some of these earlier models or to suggest more specific process-level hypotheses that can begin to fill in the 'why' of personality-psychopathology associations.

\section{Principles of trait-disorder co-development}

Principle no. 1: Trait-disorder associations are dynamic in that their mechanisms differ across persons depending upon their developmental contexts, and within person, on the basis of the idiographic histories of their traits and experience with disorder.

This principle derives from an acknowledgment of agerelated population changes in trait levels and disorders that may reflect the actions of different processes across development, and the recognition of bidirectional associations between these constructs. As such, it is highly unlikely that any one of the traditional models (e.g. spectrum, predisposition, 
and scar) can account for all or even most of the processes driving associations observed between traits and disorders over the life course.

We propose that different personality processes that can co-occur at the same time or be salient or come online at different points in the lifespan or in the history of a disorder should be the unit of analysis, rather than 'models' meant to summarize 'the' relationship between personality and disorders. As an example of these bidirectional and developmental proposals, consider the literature on the link between stressful life events and depression. It is now clear that stressful life events causally impact depression (Kendler \& Gardner, 2010), that depression causes exposure and reactivity to stressful life events (Hammen \& Brennan, 2001; Uliaszek et al., 2012), and that the link between occurrence of stress and onset of depression changes across episodes, with weaker stressors having greater impact on recurrences than on first episodes (Stroud, Davila, Hammen, \& Vrshek-Schallhorn, 2010). A correspondingly rich accounting of personality-psychopathology associations will require moving towards more developmentally informed mechanisms that can be tested in longitudinal designs and with persons exposed to different developmental pressures and varying in their experience of a disorder.

Principle no. 2: Trait levels can only be considered 'extreme' in relation to age-appropriate norms.

Cross-sectional designs using mixed-age samples provide limited and potentially misleading evidence regarding links between traits and disorders. Covarying age in analyses does not address this issue, given the well-known problems of interpretation that occur in analyses of covariance when the covariate (age) is correlated with both measures of interest (Miller \& Chapman, 2001). Minimally, trait scores should be quantified by reference to age-related norms, but such data are less available for early developmental periods. Even more informative are longitudinal studies that have power to identify individuals whose trajectories of scores (rather than score at any single time point) are non-normative relative to peers.

Principle no. 3: Processes evoked by developmental pressures vary in their timing and impact across individuals.

Chronological age is merely a proxy for the timing of the processes underlying development and provides only weak clues as to how developmental presses will be experienced psychologically. This is because individuals vary in the timing, nature, and personal meaning of their exposure to developmental pressures and in the maturity of their systems for responding to these pressures. As one example, there is evidence that even more important for adjustment than the occurrence of puberty is its timing. In comparison with 'on time' peers, girls with early and late pubertal onsets are at higher risk for depression in adolescence (Ge, Conger, \& Elder, 2001; Graber, Lewinsohn, Seeley, \& Brooks-Gunn, 1997) and exhibit elevated symptoms of psychopathology in adulthood (Graber, Seeley, Brooks-Gunn, \& Lewinsohn, 2004). Among girls with early onset puberty, some have personality profiles that fail to support adaptive responses to the new experiences that follow this transition, potentially leading to negative affect and feelings of being misunderstood by peers experiencing puberty on a different timeline (Ge et al., 2001), all of which may subsequently increase risk for psychopathology. For men, late pubertal onset has been linked to externalizing and substance use problems during emerging adulthood (Graber et al., 2004), a period typically associated with decline in these problems. Thus, the same universal developmental event can vary in its influence dependent upon its timing relative to peers. Considerations in testing processes that could link personality and psychopathology following from this principle are articulated subsequently.

First, rather than focusing on age periods (e.g. late adolescence), it is imperative to investigate transactions between specific person-level characteristics and experienced environmental contexts over time as contributors to traitdisorder co-development. One important strategy is to identify specific developmental pressures of theoretical interest. The social investment principle (Roberts, Wood, \& Smith, 2005) proposes that personality development in late adolescence to early adulthood begins with taking on new social roles (committed relationships, work, and community responsibilities). Role investment then brings about changes in identity and behaviour that increasingly match role expectations. Individuals who take on these roles do tend to exhibit subsequent trait maturation (i.e. decreases in NE and increases in CN; Lehnart, Neyer, \& Eccles, 2010; Neyer \& Asendorpf, 2001). These transitions may represent moments when the processes that tie together traits and disorders are especially salient, as the importance of achieving these milestones and consequences for failure to do so may produce sensitive periods in which risk for disorder is high for those with personality profiles that are poorly matched for these milestones. Designs that allow for denser microscopic analyses of mechanisms in the realms of identity, cognitions, and behaviour change that may produce positive versus negative adaptations to these specific transitions and those characterizing other developmental periods will be very generative.

Second, the impacts of life transitions may vary by their nature (volitional or involuntary), or by the person's trait levels or presence of disorder at the time of the transition. Compared with involuntary transitions (such as puberty), volitional transitions are open to greater influence in timing and quality from prior traits and disorders. Personality traits shape the environments in which people are embedded, a process referred to as 'selection'. Selection can heighten or minimize the likelihood that a transition will result in changes in trait or disorder levels. For example, low $\mathrm{CN}$ in adolescents may cause them to enter into some transitions (e.g. sexual initiation) earlier than peers. The early timing and relative immaturity of their personality profiles may strengthen the link between sexual initiation and poor outcomes (e.g., depression and substance abuse) for this subgroup, relative to their peers. Psychopathology may have similar effects. For example, depression in adolescence predicts subsequent sexual risk behaviours, such as condom non-use (Buka, Gortmaker, Lehrer, \& Shrier, 2006), thus heightening the likelihood that a normative transition may result in further psychopathology. 
Third, the impacts of transitions may be moderated by the broader environmental contexts in which they are navigated. Personality change is most likely when in addition to clear pressure to behave in new ways (i.e., developmental press), there is also active discouragement of old behaviours, clear guidelines about how to meet the new expectations adaptively (Caspi \& Moffitt, 1993), and selective rewards or punishment for meeting or not meeting the new expectations (Roberts, Walton, Bogg, \& Caspi, 2006). This means that the environment can support the growth of competence in various ways, potentially fostering it most in those least prepared for the transition. Socializing agents can help youth to identify areas of needed behaviour change, apply appropriate contingencies to motivate mature and competent behaviours, and draw the youths' attention to their successes in ways that helps them to integrate the new behaviours into their identities. Variations in the environment, such as the degree of positivity in relationships with socializing agents, will foster or impede these processes (Roberts \& Woods, 2006). Some of these variations may be sex-linked in that socializing agents may hold different expectations for men and women or reinforce different kinds of behavioural changes in response to developmental pressures; taken together with sex differences in trait mean levels, these selective responses may heighten risk for certain disorders in men or women at particular developmental periods.

\section{Processes contributing to trait-disorder co-development}

Our three principles suggest specific processes that may explain trait-disorder co-development. Many have parallels to or could be considered modifications to traditional personalitypsychopathology models, which we articulate subsequently. Consistent with principle no. 1 , the individual and dynamic nature of trait-disorder associations, the processes we articulate can co-exist within individuals but may also apply to greater degrees in some individuals than in others, and/or be more relevant to some trait-disorder pairings than to others.

Stagnation and recovery processes: A disorder can inhibit the processes that drive normative change in a trait, and remission of symptoms can result in change towards normative trait levels.

The stagnation hypothesis states that the presence of a disorder stunts personality development, particularly when the disorder is active during a period of expected normative change. It extends the scar model by defining the impact of a disorder on a trait in terms of normative trait trajectories and proposing that such scarring is more likely when disorders occur during developmental periods characterized by greater normative change in the trait.

What are the processes by which personality stagnation may result from psychopathology? One potential set of mechanisms concerns goals and goal-directed behaviour. The Denissen et al. (2013) regulatory model of personality proposes that behaviours indicative of traits are enacted as functions of their relations to desired goals. Behavioural dispositions regulate relations between the person's current state, salient aspects of the environment, and some standard for a future desired state (Carver \& Scheier, 2001). It follows that changes in desired goals should be causally involved in changes in traits, as individuals engage in processes meant to bring about new desired outcomes, such as selecting in or out of different environmental contexts, structuring the environment in new ways, or adopting new cognitive approaches to engaging with aspects of the environment. Experiences of psychopathology that alter goals or the perception one can achieve these goals might result in behaviour changes that become habitual with time. For example, depressive pessimism about one's competence might lead an adolescent to disengage from academic goals and select into environments consistent with academic disengagement (e.g. affiliation with peers holding similar attitudes), thus contributing to trait change away from maturation (i.e. lower $\mathrm{CN})$. In fact, there is evidence that even after recovery from MDD, formerly depressed adolescents have more school absenteeism than never-depressed adolescents (Lewinsohn, Roberts, et al., 1994).

Stagnation can have long-term effects on traits (even beyond the presence of active symptoms) because some of those with a history of the disorder will also suffer consequences for failing to achieve maturational milestones such as educational attainment or employment, or for entering deviant contexts (e.g. substance abuse leading to legal problems), thus deepening extremes of trait expression, or reducing the likelihood of progression towards normative personality development. Evidence consistent with a stagnation process would include increases over time in trait differences between disorder and no-disorder groups.

The recovery hypothesis posits that symptom remission frees personality to change towards the developmental norm. One hallmark of psychopathology is lack of behavioural and cognitive flexibility; thus, resolution of disorder may allow someone to explore new behavioural repertoires in a way that is more responsive to environmental demands. Evidence consistent with a recovery mechanism would include rate of personality change following recovery that is greater than the normative trend over a similar time span, consistent with a catching-up effect. Consistent with this hypothesis, Ormel et al. (2004) reported that measures of NE, low self-esteem, and low mastery were elevated during MDEs but returned to their pre-morbid levels after remission. Harkness, Bagby, Joffe, and Levitt (2002) found that after 3 months of antidepressant treatment, patients with MDD reported lower levels of NE, and higher levels of $\mathrm{PE}$ and $\mathrm{CN}$ in comparison with their intake scores. Importantly, as these studies did not focus on one developmental period, they cannot be interpreted in light of personality maturation. However, it seems plausible that the presence of psychopathology may explain why some individuals with extreme $\mathrm{CN}$ and NE scores in adolescence fail to attain full personality maturation despite large changes in these traits (Johnson et al., 2007). For individuals who experienced chronic courses of disorder or had extreme trait levels prior to disorder onset, the amount of change after symptom remission may not be sufficient to match their healthy peers. Some people may experience at least partial recovery, whereas others experience stagnation or even deepening of immature patterns. 
Developmental press processes: Unsuccessful adaptations to a developmental press contribute to the onset or severity of disorders, as well as to deviations in personality development.

Developmental pressures are evident during periods of normative transition or upon occurrence of stressful events that tax the person's capabilities. Normal transitions (e.g. moving from middle to high school, puberty, and dating) are more taxing when they occur simultaneously, rather than singly (Simons, Burgeson, \& Carlton-Ford, 1987). Stressful life events may also be considered developmental pressures if they call for new cognitive or behavioural accommodations (e.g. a teenager who loses a parent may have to assume caretaking responsibilities for a younger sibling). Individuals whose responses to the pressures do not meet the challenge or which do so by creating new problems (e.g. the teenager drops out of high school to care for her sibling) tend to have negative outcomes that may contribute to onset or severity of a disorder or deterioration of personality functioning. For example, although taking on adult work responsibilities is generally associated with personality maturation (Specht et al., 2011), Roberts et al. (2006) found that those who engaged in counterproductive work behaviour exhibited an increase in $\mathrm{NE}$ and decrease in $\mathrm{CN}$. The reverse is also true; persons who successfully adapt to developmental pressures are likely to experience symptom remission and/or movement towards personality maturity. For example, if the bereaved teenager stays in school and develops effective strategies for managing her time to succeed academically while caring for her sibling, her new-found competence may motivate her to spend less time drinking with friends.

These developmental press hypotheses can be conceptualized as a more specific version of the common cause model, in which life events and transitions are third variables that produce correlated changes between traits and disorders. Identifying more precise mechanisms at play in the generation, interpretation, and adaptation to developmental pressures is necessary for understanding the links between traits and disorders. One important nuance is described in Roberts and Caspi's (2003) corresponsive principle of personality development, namely that the aspects of personality that facilitate or cause people to encounter particular experiences will then be responsive to (i.e. be changed by) those same experiences, as they tend to reinforce those traits. Thus, personality processes may have all these roles: starting points in exposure to a developmental press, mechanisms that process the meaning of the press, and behavioural patterns that can change as a result of it.

Considering personality in the framework of traits alone will not fully account for these mechanisms. In some cases, developmental pressures may create new goals that are in conflict with existing traits (Freund \& Riediger, 2006). The likelihood of personality change hinges on the personal salience of these goals or strivings, and psychological resources that enable people to enact behaviours and cognitions consistent with their 'developmental projects' (i.e. the new goals perceived as important to defining success at this point in their lives), rather than their traits (McAdams \& Olson, 2010). Meeting these highly meaningful goals likely reduces risk for psychopathology as well. In other cases, responses to time-limited developmental pressures may become more permanent fixtures of personality if they become consolidated into one's identity, particularly during the formative narrative identity development period of late adolescence and early adulthood (Habermas \& Bluck, 2000). Narrative identity, the development of which is a primary task of emerging adulthood (McAdams, 1985), is an internalized story of oneself, one's past, and one's future, which serves to affirm one's choices and prepares one to take on new challenges. It can be conceptualized as a distinct layer of personality (McAdams \& Pals, 2006). When maladaptive patterns that have become habitual enough to be organized as traits are accompanied by a personal narrative consistent with these traits, subsequent person-environment interplay stabilize these processes and close off avenues for adaptive change (i.e. via cumulative continuity; Roberts \& Wood, 2006).

The predictive validity of personality for psychopathology is heightened during times of developmental press.

This is a diathesis-stress model similar to the predisposition model, but it specifically incorporates developmental context to suggest both when and why personality processes are causally involved in the development of psychopathology. It is well established that high NE predicts MDD in the context of stressful life events (Kendler, Kuhn, \& Prescott, 2004; Ormel, Oldehinkel, \& Brilman, 2001; van Os \& Jones, 1999), perhaps because those high in NE experience more subjective distress in response to stress (Bolger \& Schilling, 1991). In contrast to stressful life events that may occur at any point in the lifespan, normative transitions are windows during which many traits bear upon the ability to successfully navigate the relevant choice points. New challenges arising during transitions can evoke uncertainty, and the effects of one's behavioural choices can have longer term consequences later in the lifespan. Personality processes will influence both perceptions of these pressures and responses to them, thus affording subsequent links between traits and disorder that are less evident during more quiescent developmental periods. For example, low extraversion will be more consequential for children's depression when making a transition from middle to high school that requires establishing new friendships than it is for beginning a new term at the same school. Adolescents low in $\mathrm{CN}$ who struggle to manage their time effectively for studying will encounter more problems when they first enter college than when coasting through the last semester of high school. Thus, periods of developmental press or transition represent moments during which the connections between personality and disorder are both especially tight and potentially changeable, and therefore represent windows for especially informative empirical studies.

Individuals who deviate most from age-appropriate trait levels are those most likely to exhibit disorder presentations that are developmentally abnormal.

This is a modified pathoplasty hypothesis that focuses not on symptom severity but on developmental parameters of onset and offset. It follows from an understanding that many disorders, such as MDD and AUD, are common enough to have their own 'normative' expression patterns. 
Just as deviations from normal personality may mark greater liability to psychopathology, non-normative expressions of common disorders may reflect more deviant personality processes or inadequate responses to a developmental press. These deviations may be defined by an early onset, a chronic course, or emergence during a developmental period in the life span in which a new onset of the disorder is atypical.

\section{An empirical demonstration of developmentally informed trait-disorder models}

To provide empirical evidence regarding the importance of these processes, we describe one simple approach to using longitudinal data to test some of these developmental process-based hypotheses, taking as our examples the common disorders of MDD and AUD. Both MDD and AUD are heterogeneous categories that include multiple subtypes or risk pathways. For AUD, several theoretical subtype classification schemes on the basis of symptom severity, comorbidity, and course have been proposed (Babor, 1996; Leggio, Kenna, Fenton, Bonefant, \& Swift, 2009), and others have used statistical models to identify empirical subgroups that best account for the majority of variation in age-related trajectories of drinking and AUD (Chassin et al., 2004; Schulenberg, O'Malley, Bachman, Wadsworth, \& Johnston, 1996; Sher, Jackson, \& Steinley, 2011). For depressive disorders, there is convincing evidence that chronic/recurrent cases reflect distinct etiological pathways and more problematic outcomes than nonchronic cases (Klein, 2008). Although less consistent, the empirical evidence regarding differences between early (childhood or adolescent versus adult) onset of depressive disorders suggests that early-onset cases may be more severe and reflect unique etiological factors (Alpert et al., 1999; Hill, Pickles, Rollinson, Davies, \& Byatt, 2004; Jaffee et al., 2002; Klein et al., 1999).

Our approach to describing heterogeneity in MDD and AUD using principles of developmental psychopathology takes as a starting point the two course specifiers of onset and chronicity. The developmental psychopathology approach posits that deviations from normal development are likely to signal psychopathological conditions (Cicchetti, 1993). Analogously, for common disorders, deviations from 'normative' course trajectories likely reflect more serious dysfunction. For example, onset prior to the peak prevalence of disorder can be used to define an 'early' onset potentially indicative of greater severity or a unique etiological pathway. For both AUD and MDD, onset prior to late adolescence precedes the period of peak prevalence and is suggestive of greater severity.

Chronicity refers to the duration of symptomatic periods. For depressive disorders, diagnostic schemes classify those with symptoms lasting at least 2 years as chronic cases. For episodic depressive disorders such as MDD, chronicity can also be conceptualized as recurrence of episodes. Population rates of recurrent MDD are far lower than those of single MDEs (Eaton et al., 2008; Kessler et al., 2005), and recurrent/chronic cases are distinguishable from single episode, nonchronic cases on numerous important etiological and outcome variables, notably more extreme personality traits and personality pathology (Klein, 2008).
Definitions of chronicity can also be developmental in nature, such as persistence of symptoms in a period of life past that of peak prevalence. For example, the prevalence of AUD peaks in the early 20s and declines sharply in the mid-to-late 20s. A developmental psychopathology approach suggests that the continued presence of AUD at age 30 years is suggestive of greater severity. In addition to capturing longitudinal expressions of psychopathology across development, early onset and chronicity may identify individuals who have more homogeneous pathways to the development of these conditions than do those whose manifestation is confined to the life periods of peak prevalence.

A simple scheme can be used to create four groups $(2 \times 2$ design; Table 2$)$ of differing combinations of onset and chronicity that can be compared with each other and to a control group that did not meet criteria for the disorder in question. It is then possible to examine their incremental validities in predicting external criteria. Of course, this approach has limitations. Some persons will not fit into these categories, and the validities of the groups depend upon the sample exhibiting patterns of disorder prevalence increases, decreases, recurrences, and remissions consistent with population levels. However, this approach requires few other theoretical or statistical assumptions, and it provides an efficient way to organize heterogeneity in disorder presentation using groups that provide informative comparisons while also incorporating developmental considerations. Analytic approaches using dimensional metrics for the two markers could also be employed.

A series of studies examined the validity of this approach for AUD and MDD using the longitudinal Minnesota Twin Family Study (MTFS; Foster, Hicks, Iacono, \& McGue, in press; Hicks, Iacono, \& McGue, 2010; Wilson et al., 2014). The MTFS is a community-representative sample of two age cohorts of twins born in Minnesota, including participants entering into the study at ages $11(n=1512)$ or 17 years ( $n=1252$; Iacono, Carlson, Taylor, Elkins, \& McGue, 1999). Follow-up assessments were scheduled every $3-5$ years, with an average retention rate over $90 \%$. The referenced studies included members of the older cohort who were assessed at ages 17, 20, 24, and 29 years. For both AUD and MDD, early onset was defined as presence of the disorder by age 17 years (adolescent onset), in contrast to between ages 18 and 24 years (young adult onset), with those with age-29 onset excluded from analysis. Definitions of chronicity differed slightly across disorders. For AUD, chronicity was defined by persistence of the disorder past the period of peak population prevalence (i.e. AUD present at age 29 years in addition to at any earlier assessment); desistence was defined as no symptoms of AUD at age 29 years (following presence of AUD at an earlier assessment). For MDD, chronicity was defined by recurrence (two or more episodes). Control groups of participants who never met criteria for the target disorder through age 29 years were also included. Diagnostic and control groups were compared on a number of variables at ages 17 and 29 years.

Several convergent and discriminant findings emerged that support the validity of this developmentally informed approach. Compared with those with young adult onset, 
Table 2. Definitions of course specifiers of onset and chronicity for persons with a disorder

\begin{tabular}{|c|c|c|}
\hline & Chronic course: No & Chronic course: Yes \\
\hline \multirow[t]{5}{*}{ Early onset: No } & $\begin{array}{l}\text { Onset during the age range of peak } \\
\text { prevalence (normative onset) }\end{array}$ & $\begin{array}{l}\text { Onset during the age range of peak } \\
\text { prevalence (normative onset) }\end{array}$ \\
\hline & AND & AND \\
\hline & $\begin{array}{l}\text { Symptom duration does not extend beyond } \\
\text { the age range of peak prevalence OR }\end{array}$ & $\begin{array}{l}\text { Symptom duration extends beyond the age range } \\
\text { of peak prevalence OR }\end{array}$ \\
\hline & Single episode OR & Recurrent episodes OR \\
\hline & Short duration in absolute time & Long duration in absolute time \\
\hline \multirow[t]{4}{*}{ Early onset: Yes } & Onset prior to the age range of peak prevalence & Onset prior to the age range of peak prevalence \\
\hline & $\begin{array}{l}\text { Symptom duration does not extend beyond } \\
\text { the age range of peak prevalence OR }\end{array}$ & $\begin{array}{l}\text { Symptom duration extends beyond the age range of } \\
\text { peak prevalence OR }\end{array}$ \\
\hline & Single episode OR & Recurrent episodes OR \\
\hline & Short duration in absolute time & Long duration in absolute time \\
\hline
\end{tabular}

adolescent onset of AUD was associated with several elevated risk markers and negative outcomes at age 17 years including heavy drinking, tobacco and illicit drug use and dependence, child and adult antisocial behaviour, serious psychiatric problems, academic failure, parent-child relationship problems, and deviant peer affiliation (Foster et al., in press; Hicks et al., 2010). In contrast, persons with young adult onset, the 'normative' period of expression of AUD symptoms, exhibited few elevated risk markers at age 17 years; compared with the control group who never met criteria for an AUD, they were elevated on drinking measures only prior to age 29 years. The only variables at age 17 years that predicted persistence of AUD to age 29 years were measures of behavioural disinhibition (antisocial behaviour and low CN). At age 29 years, persistence (regardless of age of onset) was associated with heavy drinking, nicotine dependence, illicit drug use and dependence, antisocial behaviour, deviant peer affiliation, separation or divorce, and greater drinking in romantic partners.

Other important findings emerged from these analyses. For men, the adolescent-onset-persistent course group exhibited the greatest loading of risk at age 17 years and the worst outcomes at age 29 years. The adolescent-onsetdesistent group also experienced a number of severe deficits at age 17 years, but somewhat remarkably, by age 29 years, they exhibited few significant differences from individuals who never experienced AUD on measures of mental health and substance use. Most notably, in addition to remission of their AUD symptoms, their levels of drinking had declined to normative levels at age 29 years. However, compared with the control group, the adolescent-onset-desistent group failed to reach a comparable level of educational attainment and transitioned into cohabitation and parenthood at an earlier an age. The differences in outcomes between the two adolescent onset groups were not attributable to IQ at age 17 years. In terms of personality, both adolescent onset groups were higher on NE than the control group, but only the adolescent-onset-persistent group was lower on CN. Thus, although largely consistent with the recovery hypothesis, adolescent-onset-desistent participants did not escape wholly unscathed, suggesting that the deficits evident in this group in late adolescence had long-lasting negative effects that were not offset by recovery from AUD.

The adult-onset-persistent group exhibited a number of substance use and behavioural problems at age 29 years.
Relative to the control group, they were elevated on the behavioural disinhibition liability common to externalizing disorders at age 17 years but were somehow able to avoid adolescent onset of AUD and related problems such as comorbid substance use problems and academic difficulties. This could be because they experienced fewer cumulative risk factors. Finally, the adult-onset-desistent group exhibited almost no significant differences from the control group at either age 17 or 29 years. This group seemed to exemplify a 'developmentally limited' form of AUD, as symptoms were confined to the period of peak prevalence and thus 'normative' in a statistical sense, a label validated by their relatively healthy outcomes.

Results for the MDD groups (adolescent vs. young adult onset crossed with single vs. recurrent episodes) were similar with some caveats (Wilson, Hicks, Foster, Iacono, \& McGue, in press). First, in contrast to the importance of adolescent onset for AUD, recurrence was the primary marker of severity for MDD. Similar to AUD, the adolescent-onset-recurrent MDD group had the most elevated risk markers at age 17 years and poorest outcomes at 29 years. Relative to those with adult onset, those with adolescent onset of MDD reported greater nicotine and illicit drug substance use, antisocial behaviour, deviant peer affiliation, and academic and parent-child relationship problems at age 17 years. Most of these effects were confined to the adolescent-onset-recurrent group. In fact, the interaction between recurrence and adolescent onset predicted lower PE and greater alcohol use, antisocial behaviour, and antisocial peer affiliation. Relative to the never-depressed group, the adolescent-onset-single-episode group was elevated on substance use, parent-child relationship problems, and academic problems at age 17 years, but to a lesser extent than the adolescent-onset-recurrent group. Only low PE at age 17 years was associated with recurrence, which was solely attributable to the adolescent-onset-recurrent group. $\mathrm{NE}$ was the only variable at age 17 years that was elevated in those with young adult onset of MDD.

At age 29 years, recurrent MDD was associated with high $\mathrm{NE}$ and low PE, nicotine dependence, antisocial behaviour, fewer prosocial peers, work dissatisfaction, and histories of mental health treatment and suicide attempts, regardless of onset. Adolescent-onset MDD was associated with illicit drug use, history of suicide attempts, and physical abuse or 
assault at age 29 years. Relative to controls, the adult-onset groups exhibited greater NE, substance use, antisocial behaviour, and history of mental health treatment and sexual abuse or assault at age 29 years. Effect sizes, however, were always greater for the adult-onset-recurrent group, who also exhibited additional deficits of lower PE and work satisfaction, fewer prosocial peers, and more suicide attempts and physical abuse or assault. The adolescent-onset-recurrent group exhibited the most numerous and sizeable deficits relative to the control group, especially for NE, suicide attempts, illicit drug use, romantic relationship problems, and history of traumatic events. In the aggregate, the findings supported the greater importance of recurrence relative to age of onset for MDD, and that an adolescent onset with recurrence is a particularly severe subtype of MDD.

\section{The impacts of AUD and MDD onset and chronicity on personality development}

These findings supported the usefulness of onset and chronicity for organizing heterogeneity of AUD and MDD in ways that predicted indices of psychiatric severity. What has yet to be done is examine what these markers reveal about relationships between AUD and MDD and personality development. For example, do the developmental course subgroups exhibit different patterns of personality development during the transition from adolescence to adulthood? More specifically, do these groups move similarly towards growth and maturity, or does personality development stagnate among those with deviant psychopathological course? Also, do those who recover from disorders show accelerated change or a catch-up towards maturity? Finally, do prior personality trait levels predict more problematic course parameters (onset or chronicity)?

To begin to answer these questions, we present novel findings using data from the MTFS. We utilized data from participants of the age-17 cohort, who were assessed for personality using the MPQ at ages 17, 24, and 29 years. We examined the mean personality scores for the AUD and MDD onset and chronicity groups ${ }^{1}$ at each age, compared with a single control group that did not meet criteria for either AUD or MDD by age 29 years (healthy controls). Because of the known differential associations between some of the lower order scales and internalizing and externalizing disorders (Krueger et al., 1996), we focused on five lower order traits scales that show these associations: stress reaction, alienation, and aggression (NE scales), and well-being (PE scale) and control (CN scale). Well-being and control are the core component scales of their respective higher order traits and exhibited similar associations with the psychopathology groups as the higher order factors.

Figure 1 provides the trajectories for each trait in each group from ages 17 to 29 years, with the AUD and MDD

\footnotetext{
${ }^{1}$ The MDD groups were defined slightly differently than those in the study of Wilson et al. (in press). Specifically, recurrence required a major depressive episode in at least two assessment periods, rather than at least two episodes over any period. This helped to make the groups more comparable with the AUD groups, for which persistence was defined by presence of AUD in more than one assessment period.
}

groups shown in adjacent plots. Perhaps the most striking observation is the degree of discriminant validity, as some traits better differentiated the course subgroups for MDD than for AUD and vice versa. The MDD groups were more clearly differentiated on well-being and stress reaction, whereas aggression and control efficiently differentiated the AUD groups but had relatively little utility for doing so for MDD groups.

Next, we established the normative trends for personality change by looking within the healthy control group. Consistent with the maturity principle, scores for the control group were stable for well-being $\left(d_{17-29}=0.13\right)$, increased for control $\left(d_{17-29}=0.77\right)$, and decreased for alienation $\left(d_{17-29}=-1.12\right)$, aggression $\left(d_{17-29}=-1.05\right)$, and stress reaction $\left(d_{17-29}=-0.64\right)$. We then examined how each trait differed among the AUD and MDD course groups.

\section{Well-being}

Differences among the AUD groups in well-being scores were small at age 17 years, and within each group, scores were relatively stable. The adolescent-onset-persistent group exhibited slightly lower well-being scores than the other groups at age 24 years and in comparison with the desistent groups at age 29 years. For the MDD groups, only the adolescent-onset-recurrent group exhibited lower well-being scores at age 17 years $\left(d_{\text {control }}=-0.81\right)$. At ages 24 and 29 years, however, both recurrent groups had lower well-being scores than the single-episode and control groups. Thus, well-being appeared to be a marker of recurrence and greater severity, consistent with stagnation and common developmental cause processes, but potentially also the existence of threshold or sub-threshold symptoms (i.e. anhedonia) at the time of personality assessment. Well-being did not appear to predispose to new onsets of MDE, as the adult-onset groups did not differ from controls in well-being at age 17 years. Well-being scores were relatively stable within each group except for the adult-onset-recurrent group, who exhibited a medium decrease from ages 17 to 24 years $\left(d_{17-24}=-0.48\right)$. Differences between the adolescentonset-recurrent and control groups increased over time $\left(d_{\text {control }}=-1.00\right.$ at age 29 years $)$, indicating recurrence was associated with growing deviation from one's peers, consistent with the stagnation hypothesis.

\section{Stress reaction}

The adolescent-onset-desistent group was the only AUD group with elevated stress reaction scores at age 17 years $\left(d_{\text {control }}=0.84\right)$. This was followed by a sharp decline from ages 17 to 29 years $\left(d_{17-29}=-1.02\right)$, consistent with a recovery process. The adolescent-onset-persistent group was the only group that failed to exhibit a normative decline in stress reaction. As such, differences with the other groups increased over time from $d_{\text {control }}=0.23$ at age 17 years to $d_{\text {control }}=0.66$ at age 29 years. This longer term failure to make normative maturational changes is consistent with a stagnation process.

The MDD groups were stratified and elevated relative to the control group in stress reaction $\left(d_{\text {control }}=0.47\right.$ to 0.82 at age 17 years). The two single-episode groups exhibited normative decreases in stress reaction over time, although their scores remained slightly elevated relative to the control 

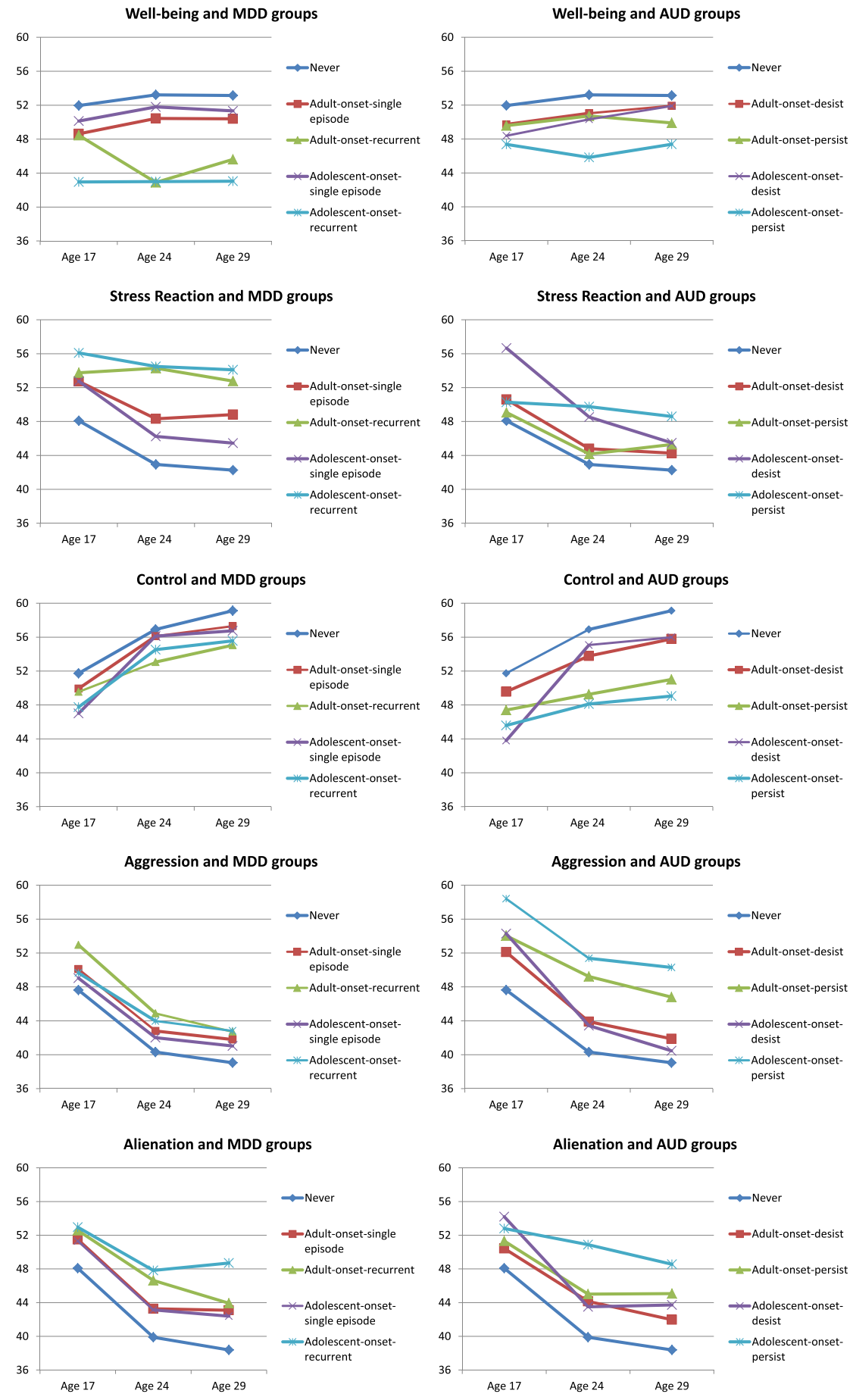

Figure 1. $T$-scores for traits at ages 17, 24, and 29 years for alcohol use disorder (AUD) and major depressive disorder (MDD) groups. $T$-scores were standardized $(M=50, S D=10)$ using the age 17 scores of the older cohort $(n=1252)$ of the Minnesota Twin Family Study (Iacono et al., 1999) at age 17 years. AUD and MDD were assessed at ages 17, 20, 24, and 29 years. For both AUD and MDD, adolescent onset was defined as onset by age 17 years, and adult onset was defined as onset between ages 18 and 24 years. For AUD, a persistent course required AUD at age 29 years and at a previous assessment; a desistent course was defined as no symptoms of AUD at age 29 years following AUD at a previous assessment. AUD groups included adult-onset-desistent course ( $n=127)$, adult-onset-persistent course $(n=85)$, adolescent-onset-desistent course $(n=55)$, and adolescent-onset-persistent course $(n=49)$. For MDD, a recurrent course was defined as a major depressive episode during at least two assessment periods. MDD groups included adult onset-single episode $(n=189)$, adult-onset-recurrent episodes $(n=58)$, adolescent-onset-single episode $(n=77)$, and adolescent-onset-recurrent episodes $(n=81)$. The never or control group $(n=421)$ included participants who had not met criteria for AUD or MDD by age 29 years.

group at age 29 years, owing to higher initial scores at age 17 years. Stress reaction scores for the recurrent groups were stable and so became increasingly deviant from the single-episode and control groups over time $\left(d_{\text {control }}=0.56\right.$ and 0.82 at age
17 years; $d_{\text {control }}=1.03$ and 1.54 at age 29 years for adult- and adolescent-onset-recurrent groups, respectively).

Several models are consistent with these findings. Evidence that the adult-onset groups were higher in stress 
reaction at age 17 years than the control group is consistent with predisposition (i.e. predicts the development of new MDEs). Those with recurrent or chronic courses failed to show the normative decline such that differences across groups on stress reaction increased over time, consistent with stagnation. Similar stagnation effects were observed for the adolescent-onset-persistent AUD group, suggesting that elevated stress reaction may be an outcome of chronic psychopathology more generally, rather than specific to MDD.

\section{Control}

Control scores increased with age to varying degrees for all AUD and MDD groups, suggesting these disorders did not fully disrupt the developmental press to increase behavioural control. Control did not differentiate the MDD groups, although scores for the adolescent-onset-single-episode group increased steeply from ages 17 to 24 years $\left(d_{17-24}=0.75\right)$ so that they reached parity with the control group, consistent with a recovery process. By contrast, control scores clearly stratified the AUD groups at age 17 years, and the groups differed in rates of change in this trait. Both persistent groups exhibited small increases from ages 17 to 29 years, resulting in greater differences relative to the control group over time $\left(d_{\text {control }}=-0.47\right.$ and -0.64 at age 17 years; $d_{\text {control }}=-0.79$ and -1.07 at age 29 years for adult- and adolescent-onset-persistent groups, respectively). Thus, findings for control and AUD were consistent with both predisposition and stagnation. By contrast, both desistent groups exhibited maturation. The adult-onset-desistent group increased at a similar rate to that of the control group. The adolescent-onset-desistent group, however, exhibited an especially steep increase from age 17 to 24 years $(d=1.02)$, suggesting both a context of high initial risk and strong recovery thereafter.

\section{Aggression}

Aggression scores declined for all AUD and MDD groups from ages 17 to 29 years, consistent with normative trait maturation. AUD groups were clearly stratified and elevated relative to controls at age 17 years, and they differed substantially in amounts of mean-level change from ages 17 to 29 years. The two desistent groups decreased more than the control group $\left(d_{17-29}=-1.22\right.$ and -1.52 for adult- and adolescent-onset-desistent groups, respectively), thereby reducing differences from the control group over time. In contrast, the persistent groups exhibited smaller mean-level changes than controls, resulting in larger differences from the control group at age 29 years. These findings are consistent with predisposition for development of AUD, as well as with stagnation and recovery processes, among those with persistent versus desistent AUD, respectively.

All MDD groups except the adolescent-onset-recurrent group exhibited normative decreases in aggression that were similar to that of controls, consistent with a stagnation effect of MDD on aggression in the most pathological group. Only the adult-onset-recurrent group was elevated in aggression relative to the control group at age 17 years, consistent with a predisposition process. The two recurrent MDD groups had slightly elevated aggression scores relative to controls at age 29 years.

\section{Alienation}

In comparison with the other traits we explored, alienation scores exhibited a unique pattern of associations with the psychopathology groups. At age 17 years, all AUD $\left(d_{\text {control }}=0.24\right.$ to 0.60$)$ and $\operatorname{MDD}\left(d_{\text {control }}=0.33\right.$ to 0.50$)$ groups exhibited small to medium elevations in alienation relative to controls. All groups also exhibited normative decreases in alienation scores. However, none of the groups decreased as much as the control group. As a consequence, differences from the control group increased from ages 17 to 29 years for all AUD $\left(d_{\text {control }}=0.38\right.$ to 1.13$)$ and $\operatorname{MDD}\left(d_{\text {control }}=0.47\right.$ to 0.99$)$ groups. These findings suggest both predisposing and stagnation processes. They also suggest that alienation may be a particularly strong general personality marker of psychopathology.

\section{Child personality prior to disorder onset}

One limitation to these analyses was that they could not determine if adolescent onset course groups were deviant in personality at age 17 years owing to current AUD or MDD symptoms, or owing to personality deviations preceding onset of symptoms. To address this, we utilized data collected at the intake (age 11 years) assessment of the 11-year-old cohort of the MTFS. Ratings of trait descriptions designed to assess MPQ traits were completed by mothers and teachers (for reliability and validity, see Cukrowicz, Taylor, Schatschneider, \& Iacono, 2006; Hicks et al., 2014b; Tackett, Krueger, Iacono, \& McGue, 2008). These trait ratings were robust predictors of substance use initiation and onset of substance use disorders in adolescence and young adulthood (Hicks et al., 2013; Hicks, Iacono, \& McGue, 2014a).

The age-11 cohort has not yet completed the age-29 assessment; therefore, we could not examine how well traits at age 11 years differentiated our AUD and MDD onset and chronicity groups. However, in a previous report (Hicks et al., 2012), we compared AUD groups wherein we examined adolescent versus adult onset and desistent ( 0 symptoms of AUD) or persistent (AUD) course out to age 24 years. Compared with a control group with no AUD by age 24 years, the two adolescent onset groups had elevated NE at age 11 years $\left(d_{\text {control }}=0.51\right.$ to 0.57$)$, and all the AUD groups had low $\mathrm{CN}$ at age 11 years with medium effects for the adult-onset $\left(d_{\text {control }}=-0.43\right)$ and adolescent-onset-desistent $\left(d_{\text {control }}=-0.56\right)$ groups, and a large effect for the adolescent-onset-persistent group $\left(d_{\text {control }}=-1.00\right)$. Childhood NE predicted onset (predisposition), whereas low $\mathrm{CN}$ in childhood predicted persistence and severity of AUD (modified pathoplasty).

We sought to further understand how childhood personality related to later AUD and MDD to disentangle associations that predicted disorder onset from those that were concomitants or outcomes. For MDD, we compared personality in two diagnostic groups at age 11 years: one with onset of MDD by age 11 years and the other who had no symptoms of MDD at age 11 years but subsequent onset between ages 11 and 14 years. For AUD, symptoms were too rare at age 11 years to make meaningful comparisons. Therefore, we focused on age of first drink, defined as drinking without a parent's permission (a robust predictor of risk for AUD; 
Grant \& Dawson, 1997; McGue et al., 2001). We compared two groups: one that initiated alcohol use by age 11 years and another that initiated between ages 11 and 14 years. Both the MDD and alcohol use groups were compared with a control group who reported no symptoms of depression and did not initiate alcohol use by age 14 years.

Figure 2 displays the scores for 10 of the MPQ lower order traits at age 11 years for the MDD and alcohol use groups. Interestingly, the profiles of the two MDD groups were almost indistinguishable at age 11 years, despite one group having already experienced an MDE and the other having not yet reported a single symptom of MDD. Both groups were low in well-being $\left(d_{\text {control }}=-0.54\right.$ and -0.60 for MDD onset by ages 11 and 14 years, respectively) and elevated on each NE scale, particularly stress reaction $\left(d_{\text {control }}=0.87\right.$ and 0.64 for MDD onset at ages 11 and 14 years, respectively). Finally, the two MDD groups had lower scores on the $\mathrm{CN}$ scales of control $\left(d_{\text {control }}=-0.45\right.$ and -0.65 for MDD onset at ages 11 and 14 years, respectively) and traditionalism $(d=-0.59$ and -0.60 for MDD onset at ages 11 and 14 years, respectively), but not harm avoidance. These findings indicate there is a distinctive personality profile associated with early onset MDD that is evident prior to symptom onset (predisposition): low dispositional well-being; lack of engagement and enjoyment in striving activities and likely low self-confidence; elevated negative affect as expressed in sensitivity to stress, anxiety, alienation, irritability, and aggression; poor impulse control and low conscientiousness; and a failure to accept and conform to conventional ethical values. This configuration of traits may serve as 'pre-depression' personality structure that may select these individuals into and be sensitive to the effects of stressful events and problematic interpersonal relationships, as well as complicate adjustment to normative developmental transitions.

The two alcohol initiation groups also exhibited personality elevations at age 11 years relative to controls. In contrast to the findings for MDD, the effect sizes were much larger for the group that initiated by age 11 years relative to those
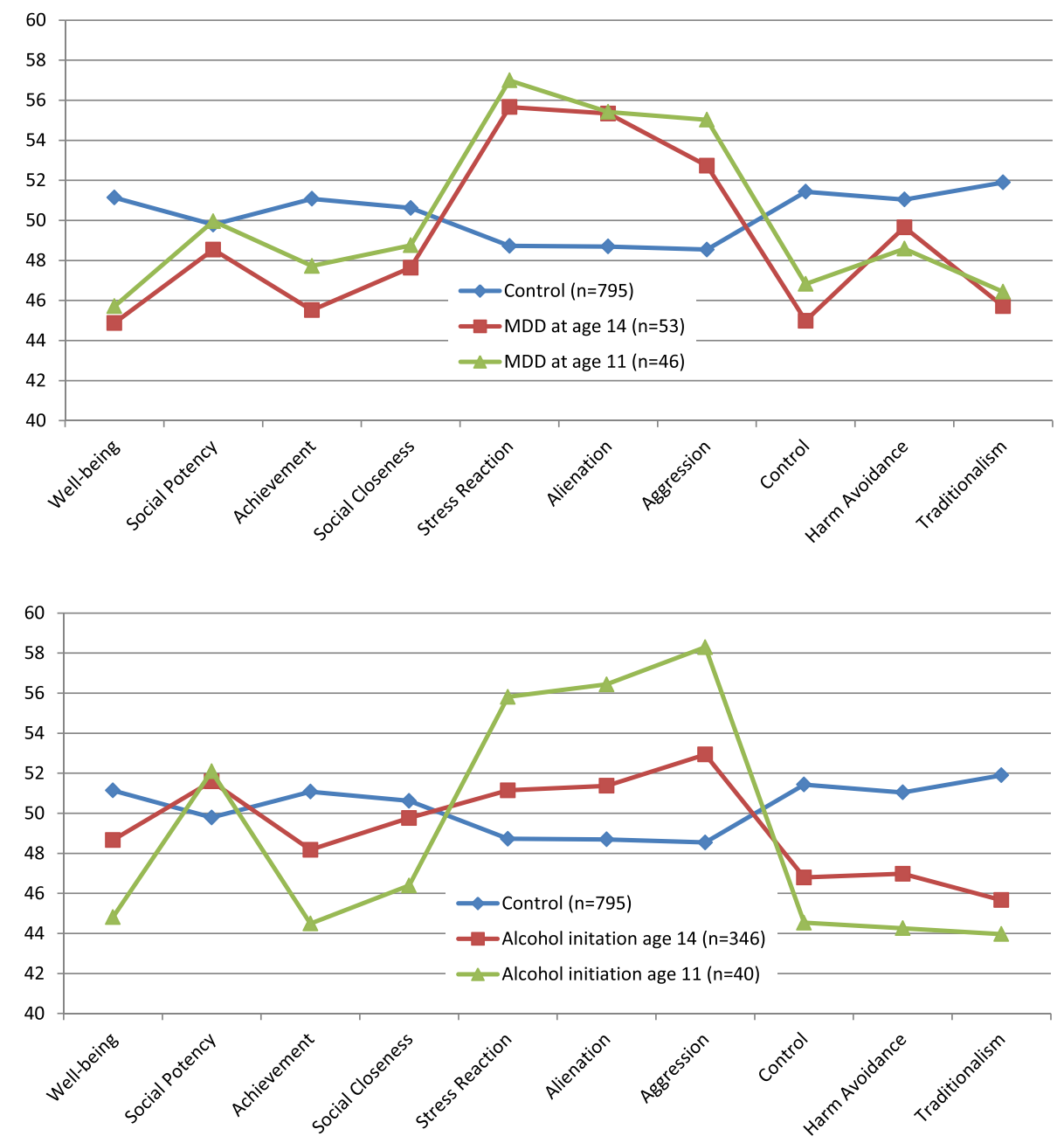

Figure 2. Personality scores at age 11 years for major depression and alcohol initiation groups. $T$-scores $(M=50, S D=10)$ for the traits were standardized using the younger cohort $(n=1512)$ of the Minnesota Twin Family Study (Iacono et al., 1999). The MDD at age 11 group included participants with a lifetime diagnosis of MDD at age 11 years. MDD at age 14 years included participants who had no symptoms of MDD at age 11 years but had a diagnosis of MDD at age 14 years. The alcohol initiation age 11 group included those participants who used alcohol by age 11 without their parents' permission. The alcohol initiation age 14 group included participants who initiated alcohol use between ages 11 and 14 years. The control group included participants who did not meet criteria for MDD by age 14 years or initiate alcohol use by age 14 years. 
that initiated between 11 and 14. The initiation-by-age-11 group was lower than controls on three PE scales: well-being $\left(d_{\text {control }}=-0.60\right)$, achievement $\left(d_{\text {control }}=-0.66\right)$, and social closeness $\left(d_{\text {control }}=-0.41\right)$, whereas the initiation-by-age14 group had no deviations on these scales greater than I 0.30l. Thus, low PE may be an outcome of alcohol use (stagnation) or specifically related only to very early use (modified pathoplasty). The initiation-by-age-11 group was higher than controls on all NE scales (range 0.65 to 0.91 ), whereas the initiation-by-age-14 group was high only on aggression $\left(d_{\text {control }}=0.44\right)$, suggesting $\mathrm{NE}$ elevations are results of alcohol use or markers of more deviant forms of use rather than causes of initiation, with the exception of aggression. Both alcohol initiation groups were low on the three $\mathrm{CN}$ scales, although the effects were slightly larger for the initiation-by-age-11 $\left(d_{\text {control }}=-0.96\right.$ for $\left.\mathrm{CN}\right)$ than the initiation-by-age-14 $\left(d_{\text {control }}=-0.66\right.$ for $\left.\mathrm{CN}\right)$ group.

The alcohol-initiation-by-age-11 and the two MDD groups were of nearly equal size. The alcohol-initiation-byage-14 group, however, was much larger than the corresponding group (onset between 11 and 14 years) for MDD, comprising roughly $25 \%$ of the sample. Consequently, personality deviations at age 11 years were smaller, although the combination of high aggression and low $\mathrm{CN}$ was clearly a marker of risk. The personality structure of early alcohol initiators was one of aggressive disinhibition, with elevations on all the NE scales, low CN scale scores, low well-being, and lack of positive engagement with people and goal striving. This personality profile was very similar to that for antisocial personality disorder in late adolescence-early adulthood (Krueger et al., 1996), suggesting that the personality structure for serious and chronic externalizing psychopathology may already be in place by middle childhood.

These analyses revealed the incremental utility of obtaining trait measures that precede normative periods of disorder onset for distinguishing among competing causal models. Of course, the greater the time between trait assessment and disorder onset, the more confidently one can differentiate between traits that are predisposing and those potentially marking the first signs of disorder (precursors). Indeed, a small but fascinating literature has shown that very early measures of traits collected in the preschool and early childhood periods can predict later emergence of both internalizing and externalizing problems (Caspi, Moffitt, Newman, \& Silva, 1996; van Os \& Jones, 1999). Such early trait markers may identify variables close to the origins of causal pathways to disorder, but the number of possible intervening pathways and lower stabilities of early childhood trait measures (Roberts \& DelVecchio, 2000) means that interpretations regarding the processes linking traits and ultimate development of disorder are necessarily more speculative than those on the basis of later trait assessments. It is possible that early traits lack direct continuity with later psychopathology because temperament in early childhood is defined more by dispositional style and less by stabilizing influences that come online near middle childhood, such as characteristic adaptations (motivations, plans, and goals) that serve to consolidate personality structure and initiate processes linking personality to agentic responses to environmental demands. Nonetheless, early measures are critical pieces of the larger effort to understand development of trait-disorder associations and can potentially identify individuals for more intensive study as they move through developmental windows of higher risk for disorder onset.

\section{Tracking personality-psychopathology co-development using other strategies}

The data we presented clearly showed disorders and traits evolving in systematic ways within a particular developmental period (early adolescence through early adulthood) characterized by both prototypical trajectories and individual deviations from these group trends. Other investigators have utilized longitudinal data to chart dynamic relations between traits and disorders using different approaches. Littlefield et al. (2009), Littlefield, Sher, and Steinley (2010), Littlefield, Sher, and Wood (2010), and Littlefield, Verges, Wood, and Sher (2012) examined the co-development of personality and problematic alcohol involvement in a college sample enriched for AUD that has been followed from ages 18 to 35 years. Taking both variable-centred (latent growth curves and latent change models; Littlefield et al., 2009, 2012) and personcentred (finite mixture modelling; Littlefield, Sher, \& Steinley, 2010) approaches, they consistently found that changes in neuroticism and impulsivity were correlated with changes in problematic alcohol use, evidence consistent with a common developmental process. Importantly, Littlefield et al. (2009) and Littlefield, Sher, and Wood (2010) also tested whether certain variables could account for these correlated changes. For example, entering into marriage and/or parenthood was associated with steeper declines in both neuroticism and problematic alcohol use but did not account for the correlation between their changes. In contrast, changes in drinking motives - specifically the motive of drinking to cope with emotional problems-partially mediated the associations between changes in problematic alcohol use and neuroticism and impulsivity (Littlefield, Sher, \& Steinley, 2010).

Kendler et al. (1993) examined the associations among neuroticism, lifetime MDD, and prospective 1-year occurrence of MDD in a large female twin sample. Neuroticism was associated with lifetime MDD and predicted new onsets over the next 12 months. Adjusting for neuroticism at Time 1 , those with new occurrence of MDD in the intervening period had higher neuroticism at Time 2, especially those with current MDD at Time 2. After controlling for their common genetic and environmental influences, the bestfitting twin model indicated that MDD had a small causal influence on neuroticism, consistent with a stagnation process. These findings were then replicated in a large sample of male twins (Fanous et al., 2007). Notably, these two studies were longitudinal but not developmentally informed as the samples included adults of a wide age range, varying in proximity to periods of greatest change in NE traits.

De Bolle et al. (2012) examined associations between Big Five traits and internalizing and externalizing problems (both assessed with maternal report) in a mixed community and clinic-referred sample of children ages 8 to 14 years. Changes in neuroticism and benevolence (similar to agreeableness) were consistently and relatively strongly associated 
with changes in both internalizing and externalizing problems. Internalizing also predicted increases in neuroticism, and externalizing predicted decreases in benevolence, although to smaller degrees. These findings were consistent with common developmental processes and the scar model.

Each of these studies provided additional demonstration that longitudinal data can be very useful for filling out the picture of co-development of traits and disorders, as well as for conducting tests of possible contributors to their codevelopment. Ultimately, to test the validity of predictions derived from a developmental perspective on traits and disorders, many more studies of this kind will be needed, as well as those using alternative methods, examining other developmental windows, and explicitly incorporating measures of particular developmental pressures and transitions and individual perceptions of and responses to these developmental contexts.

\section{Conclusions}

In the past 20 years, individual differences in personality constructs have become a central focus of etiological research on many clinical syndromes. Despite availability of models to guide investigations of the natures of those relations, very few (if any) definitive conclusions have been reached other than that traits and disorders are correlated with each other. One likely reason for this disappointing state is that the studies necessary to test and reject different models are more difficult to execute than cross-sectional designs. Moreover, many researchers have failed to be appropriately circumspect regarding the limitations of cross-sectional data. As a result, there has been a tendency to conclude, perhaps prematurely, that covariation between trait and disorder measures indicates these domains should be considered isomorphic (i.e. the spectrum model).

In our view, the most dominant theoretical perspective, the spectrum model, eliminates or minimizes valid conceptual and empirical distinctions between traits and disorders that should be preserved. This model reduces these two domains to common underlying dimensions labelled in traditional trait language (e.g. neuroticism), which are presumed to be the etiological sources of trait and symptom expression. As argued by Cramer et al. (2012), the conceptual model guiding this approach can be critiqued on both statistical and theoretical grounds. We are not the only ones to examine the co-development of traits and disorders, and the most consistent finding is that changes in each are correlated with the other. Much more difficult to articulate, however, are the mechanisms underlying these correlated changes. Neither the ability to construct measures that indicate higher order traits nor the presence of factors underlying multiple psychopathological syndromes is itself an explanation. Rather, these construct measures are summary variables that reflect aggregate tendencies to feel, think, and behave in particular ways, not direct indices of the connections that exist among thoughts, behaviours, and feelings within a person over time. Coherent individual differences are emergent properties of people that are the observable manifestations or endpoints of many other processes, dynamically changing over time. When we find that a measure of a disorder and a measure of a trait are interrelated in a specific way, we are relating two summary constructs, not explaining why the disorder or trait is present or detailing the processes that link them. To begin to answer such questions, models that articulate potential mechanisms of co-development will be particularly useful.

The field has devoted considerably more energy to understanding both personality and psychopathology structures than processes, such that refinements to structural models receive considerable discussion, whereas mechanistic questions remain largely unanswered. The assumptions of spectrum models are seldom rigorously tested, and more rarely are they compared with process-oriented models. Although structural studies often include hundreds or even thousands of participants, at this point, their results yield modest incremental knowledge for understanding causal processes, evolving over time, that link personality and psychopathology constructs. At the most basic level, the presence of individual differences in timing and degree of developmental changes in both constructs (i.e. their means and variances) indicates that the structure of inter-individual variation as revealed by factor analysis will very likely differ from the structure of these same constructs within persons over time (Molenaar \& Campbell, 2009). If real progress is to be made in discovering causal processes rather than in confirming and making progressively minor refinements to the conceptual space described by individual differences in traits at the population level, the field needs to critically evaluate the methods, designs, and hypotheses upon which it has become reliant.

Moving forward, it will be necessary to identify means of testing more focused and risky hypotheses that concern process-based constructs and to implement multiple designs that in the aggregate allow for stronger causal inferences. For example, dense longitudinal assessment designs (e.g. experience sampling) measuring personality relevant processes such as mood states, appraisals of stressors, behaviours, and goals in interaction with situational characteristics may prove particularly important for testing mechanistic hypotheses about causal pathways between trait constructs and symptoms (e.g. Hofmann, Baumeister, Förster, \& Vohs, 2012; Jahng et al., 2011; Kashdan \& Steger, 2006; Wichers et al., 2007). Although effects of any hypothesized mechanisms may be small, they will prove more illuminating than cross-sectional studies that detect large associations but are only able to stipulate varying degrees of overlap among variables with no insights into their origins or the extent to which they apply to any individual.

To enact a framework for progress, the personalitypsychopathology field needs to embrace and thoughtfully integrate developmental theory and methods. In this paper, we reviewed basic but foundational observations regarding (i) normative changes in personality, (ii) age-related changes in disorders, and (iii) the importance of deviation from these normative trends as operationalized by course specifiers of onset and chronicity. We then used an empirical example to integrate these basic observations into a coherent framework to chart the co-development of traits and disorders across a developmental period characterized by changing tasks and goals and subsequent pressures to adapt to these shifting 
contexts. We found coherent patterns of associations between traits and disorders, and this approach also predicted numerous indicators of competence in adapting to one's psychosocial context. We believe this explicitly developmental approach provides a more concrete foundation than do prior theoretical models that were derived before the field had as deep an understanding of how traits change over development. Advances in personality science provide an exciting opportunity for those interested in understanding why traits and disorders are correlated to design more sophisticated research programs that leverage developmental theory to address the complex questions surrounding dynamic associations between traits and disorders. Similarly, some of the processes studied by psychopathology researchers (e.g. scarring) may be useful for thinking not just about the effects of disorders upon personality development but also the ways in which normal developmental transitions may exert lingering impacts on personality. For example, individual differences in adaptation to challenging life transitions such as moving to high school or starting romantic relationships may impact personality development beyond the effects of pre-existing personality traits.

We proposed three principles and several models that are informed by a developmental framework. These principles include that the meaning of trait deviations can only be understood relative to age-related norms, that trait-disorder associations are dynamic and vary depending on developmental context and an individual's history of the disorder, and that the timing and impact of developmental pressures will vary across individuals. These principles suggest specific hypotheses that can be conceptualized as developmentally informed modifications of earlier personality-psychopathology models. These modifications include the prediction that the experience of disorder can stunt normative personality maturation and that remission of symptoms lends itself to recovery or catching-up of normative personality maturity, perhaps only incompletely. At the same time, persons who struggle to adapt to developmental pressures are likely to experience both disorders and failures to make normative changes in personality. Finally, personality traits are risk factors for disorders as articulated in diathesis-stress models, or as subtypes related to severity that contribute to atypical presentations of disorder. Our empirical examples identified instances of each of these processes. These processes can be applicable to different degrees in different people, can be relevant at different points in the lifespan to the same person, and can vary with respect to different aspects of personality or manifestation of disorder. This further reinforces that no single model can account for all the patterns of trait-disorder associations, as multiple processes are likely at work. It is necessary, however, to maintain distinctions among constructs and to integrate developmental processes in order to identify the causes and processes that underlie three interrelated and key elements of person-level variation: competence, personality, and psychopathology. We challenge the field to test the ideas we have outlined and to propose additional models or principles suggested by new data on personality development.

\section{ACKNOWLEDGEMENTS}

This work was supported by United States Public Health Service grant R01 DA034606 from the National Institute on Drug Abuse. Brian M. Hicks was also supported by grant K01 DA025868 from the National Institute on Drug Abuse. We thank William G. Iacono and Matt McGue for allowing us to present data from the MTFS, which was supported by grants U01 DA024417, R37 DA005147, and R01 DA036216 from the National Institute on Drug Abuse, and R01 AA009367 from the National Institute on Alcohol Abuse and Alcoholism. The authors report no conflicts of interest. The views expressed are solely those of the authors.

\section{SUPPORTING INFORMATION}

Additional supporting information may be found in the online version of this article at the publisher's web site.

\section{REFERENCES}

Alpert, J. E., Fava, M., Uebelacker, L. A., Nierenberg, A. A., Pava, J. A., Worthington, J. R., \& Rosenbaum, J. F. (1999). Patterns of axis I comorbidity in early-onset versus late-onset major depressive disorder. Biological Psychiatry, 46, 202-211.

Anderson, J. C., Williams, S., McGee, R., \& Silva, P. (1987). DSM$I I I-R$ disorders in preadolescent children. Archives of General Psychiatry, 44, 69-76.

Angold, A., Costello, E. J., \& Worthman, C. M. (1998). Puberty and depression: The roles of age, pubertal status and pubertal timing. Psychological Medicine, 28, 51-61.

Arnett, J. J. (2000). Emerging adulthood: A theory of development from the late teens through the twenties. American Psychologist, 55, 469-480.

Babor, T. F. (1996). The classification of alcoholics: Typology theories from the $19^{\text {th }}$ century to the present. Alcohol Health and Research World, 20, 6-14.

Bachman, J. G., O’Malley, P. M., Schulenberg, J. E., Johnston, L. D., Bryant, A. L., \& Merline, A. C. (2002). The decline of substance use in young adulthood: Changes in social activities, roles, and beliefs. Mahwah, NJ: Erlbaum.

Bachman, J. G., Wadsoworth, K., O'Malley, P., Johnston, L., \& Schulenberg, J. (1997). Smoking, drinking, and drug use in young adulthood: The impacts of new freedoms and new responsibilities. Mahwah, NJ: Erlbaum.

Baldwin, S. A., \& Hoffman, J. P. (2002). The dynamics of selfesteem: A growth-curve analysis. Journal of Youth and Adolescence, 31(2), 101-113.

Baltes, P. B. (1987). Theoretical propositions of life-span developmental psychology: On the dynamics between growth and decline. Developmental Psychology, 23(5), 611-626.

Birkeland, M. S., Melkevik, O., Holson, I., \& Wold, B. (2012). Trajectories of self-esteem development during adolescence. Journal of Adolescence, 35, 43-54.

Birmaher, B., Ryan, N. D., Williamson, D. E., Brent, D. A., Kaufman, J., Dahl, R. W., ... Nelson, B. (1996). Childhood and adolescent depression: A review of the past 10 years. Part I. Journal of the American Academy of Child and Adolescent Psychiatry, 35, 2427- 2539.

Blonigen, D. M., Carlson, M. D., Hicks, B. M., Krueger, R. F., \& Iacono, W. G. (2008). Stability and change in personality traits from late adolescence to early adulthood: A longitudinal twin study. Journal of Personality, 76, 229-266.

Bolger, N., \& Schilling, E. A. (1991). Personality and the problems of everyday life: The role of neuroticism in exposure and reactivity to daily stressors. Journal of Personality, 59(3), 355-386. 
Buka, S., Gortmaker, S., Lehrer, J. A., \& Shrier, L. A. (2006). Depressive symptoms as longitudinal predictors of sexual risk behaviors among US middle and high school students. Pediatrics, 118(1), 189-200.

Carver, C. S., \& Scheier, M. F. (2001). On the self-regulation of behavior. New York, NY: Cambridge University Press.

Caspi, A., Moffitt, T. E. (1993). When do individual differences matter? A paradoxical theory of personality coherence. Psychological Inquiry, 4, 247-271.

Caspi, A., Moffitt, T. E., Newman, D. L., \& Silva, P. A. (1996). Behavioral observations at age 3 years predict adult psychiatric disorders: Longitudinal evidence from a birth cohort. Archives of General Psychiatry, 53, 1033-1039.

Caspi, A., Roberts, B. W., \& Shiner, R. L. (2005). Personality development: Stability and change. Annual Review of Psychology, $56,453-484$.

Chassin, L., Flora, D. B., \& King, K. M. (2004). Trajectories of alcohol and drug use and dependence from adolescence to adulthood: The effects of familial alcoholism and personality. Journal of Abnormal Psychology, 113, 483-498.

Chen, K., \& Kandel, D. B. (1995). The natural history of drug use from adolescence to the mid-thirties in a general population sample. American Journal of Public Health, 85, 41-47.

Church, A. T. (1994). Relating the Tellegen and five-factor models of personality structure. Journal of Personality and Social Psychology, 67, 898-909.

Cicchetti, D. (1993). Developmental psychopathology: Reactions, reflections, projections. Developmental Review, 12, 471-502.

Clark, L. A. (2005). Temperament as a unifying basis for personality and psychopathology. Journal of Abnormal Psychology, 114, 505-521.

Clark, L. A., \& Watson, D. (1991). Tripartite model of anxiety and depression: Psychometric evidence and taxonomic implications. Journal of Abnormal Psychology, 100, 316-336.

Clark, L. A., \& Watson, D. (1999). Temperament: A new paradigm for trait psychology. In L. A. Pervin, \& O. P. John (Eds.), Handbook of personality: Theory and research (2nd ed., pp. 399-423). New York: Guilford Press.

Costa, P. T., Terracciano, A., \& McCrae, R. R. (2001). Gender differences in personality traits across cultures: Robust and surprising findings Journal of Personality and Social Psychology, 81, 322-331.

Costello, E. J., Erkanli, A., \& Angold, A. (2006). Is there an epidemic of child or adolescent depression? Journal of Child Psychology and Psychiatry, 47, 1263-1271.

Cramer, A. O. J., van der Sluis, S., Noordhof, A., Wichers, M., Geschwind, N., Aggen, S. H., ... Borsboom, D. (2012). Dimensions of normal personality as networks in search of equilibrium: You can't like parties if you don't like people. European Journal of Personality, 26, 414-431.

Cukrowicz, K. C., Taylor, J., Schatschneider, C., \& Iacono, W. G. (2006). Personality differences in children and adolescents with attention deficit/hyperactivity disorder, conduct disorder, and controls. Journal of Child Psychology and Psychiatry, 47, 151-159.

De Bolle, M., Beyers, W., De Clercq, B., \& De Fruyt, F. (2012). General personality and psychopathology in referred and nonreferred children and adolescents: An investigation of continuity, pathoplasty, and complication models. Journal of Abnormal Psychology, 121, 958-970.

Denissen, J. J. A., van Aken, M. A. G., Penke, L., \& Wood, D. (2013). Self-regulation underlies temperament and personality: An integrative developmental framework. Child Development Perspectives, 7(4), 255-260.

Denissen, J. A., van Aken, M. A., \& Roberts, B. W. (2011). Personality development across the lifespan. In The Wiley-Blackwell handbook of individual differences (pp. 75-100). NY: Wiley \& Sons.

Donnellan, M. B., Conger, R. D., \& Burzette, R. G. (2007). Personality development from late adolescence to young adulthood: Differential stability, normative maturity, and evidence for the maturity-stability hypothesis. Journal of Personality, 75, 237-263.

Duggan, C. F., Sham, P., Lee, A. S., \& Murray, R. M. (1991). Does recurrent depression lead to a change in neuroticism? Psychological Medicine, 21, 985-990.
Durbin, C. E., Hicks, B. M., Blonigen, D. M., Johnson, W., Iacono, W. G., \& McGue, M. (under review). Personality trait change across late childhood to young adulthood: Evidence for nonlinearity and sex differences in change.

Eaton, N. R., Krueger, R. F., Markon, K. E., Keyes, K. M., Skodol, A. E., Wall, M., ... Grant, B. F. (2013). The structure and predictive validity of internalizing disorders. Journal of Abnormal Psychology, 122, 86-92.

Eaton, W. W., Shao, H., Nestadt, G., Lee, B.H., Bienvenu, J., \& Zani, P. (2008). Population-based study of first onset and chronicity in major depressive disorder. Archives of General Psychiatry, 65(5), 513-520.

Egger, H. L., \& Angold, A. (2006). Common emotional and behavioral disorders in preschool children: Presentation, nosology, and epidemiology. Journal of Child Psychology and Psychiatry, 47, 313-337.

Else-Quest, N. M., Hyde, J. S., Goldsmith, H. H., \& Van Hulle, C. A. (2006). Gender differences in temperament: A meta-analysis. Psychological Bulletin, 132(1), 33.

Eysenck, H. J., \& Eysenck, M. E. (1985). Personality and individual differences: A natural science approach. New York: Plenum.

Fanous, A. H., Neale, M. C., Aggen, S. H., \& Kendler, K. S. (2007). A longitudinal study of personality and major depression in a population-based sample of male twins. Psychological Medicine, 37, 1163-1172.

Feingold, A. (1994). Gender differences in personality: A meta-analysis. Psychological Bulletin, 116, 429-435.

Foster, K. T., Hicks, B. M., Iacono, W. G., \& McGue, M. (in press). Adolescent risk factors and adult outcomes associated with an adolescent onset and persistent course of alcohol dependence in women. Psychology of Addictive Behaviors.

Freund, A. M., \& Riediger, M. (2006). Goals as building blocks of personality and development in adulthood. In D. K. Mrozek, \& T. D. Little (Eds.), Handbook of personality development (pp. 353-372). Mahwah, NJ: Lawrence Erlbaum Associates Publishers.

Ge, X., Conger, R. D., \& Elder, G. H. (2001). Pubertal transition, stressful life events, and the emergence of gender differences in adolescent depressive symptoms. Developmental Psychology, 37(3), 404-417.

Goldberg, L. R. (1990). An alternative "description of personality": The Big Five factor structure. Journal of Personality and Social Psychology, 59, 1216-1229.

Graber, J. A., Lewinsohn, P. M., Seeley, J. R., \& Brooks-Gunn, J. (1997). Is psychopathology associated with the timing of pubertal development? Journal of the American Academy of Child and Adolescent Psychiatry, 36, 1768-1776.

Graber, J. A., Seeley, J. R., Brooks-Gunn, J., \& Lewinsohn, P. M. (2004). Is pubertal timing associated with psychopathology in young adulthood? Journal of the American Academy of Child \& Adolescent Psychiatry, 43(6), 718-726.

Grant, B. F., \& Dawson, D. A. (1997). Age at onset of alcohol use and its association with DSM-IV alcohol abuse and dependence: Results from the National Longitudinal Alcohol Epidemiologic Survey. Journal of Substance Abuse, 9, 103-110.

Habermas, T., \& Bluck, S. (2000). Getting a life: The emergence of the life story in adolescence. Psychological Bulletin, 126, 748-769.

Hammen, C., \& Brennan, P. (2001). Depressed adolescents of depressed and nondepressed mothers: Tests of an interpersonal impairment hypothesis. Journal of Consulting and Clinical Psychology, 69(2), 284-292.

Hankin, B. L., \& Abramson, L. Y. (2001). Development of gender differences in depression: An elaborated cognitive vulnerabilitytransactional stress theory. Psychological Bulletin, 27, 773-796.

Harkness, K. L., Bagby, R. M., Joffe, R. T., \& Levitt, A. (2002). Major depression, chronic minor depression, and the five-factor model of personality. European Journal of Personality, 16, 271-281.

Hasin, D. S., Stinson, F. S., Ogburn, E., \& Grant, B. F. (2007). Prevalence, correlates, disability, and comorbidity of DSM-IV alcohol abuse and dependence in the United States-Results from the National Epidemiologic Survey on Alcohol and Related Conditions. Archives of General Psychiatry, 64, 830-842. 
Hicks, B. M., \& Zucker, R. A. (2014). Alcoholism: A lifespan perspective on etiology and course. In M. Lewis, \& K. Rudolph (Eds.), Handbook of developmental psychopathology (3rd ed.). New York: Springer.

Hicks, B. M., Durbin, C. E., Blonigen, D. M., Iacono, W. G., \& McGue, M. (2012). Relationship between personality change and the onset and course of alcohol dependence in young adulthood. Addiction, 107, 540-548.

Hicks, B. M., Iacono, W. G., \& McGue, M. (2010). Consequences of an adolescent onset and persistent course of alcohol dependence in men: Adolescent risk factors and adult outcomes. Alcoholism: Clinical \& Experimental Research, 34, 819-833.

Hicks, B. M., Iacono, W. G., \& McGue, M. (2014a). Identifying childhood characteristics that underlie pre-morbid risk for substance use disorders: Socialization and boldness. Development and Psychopathology, 26, 141-157.

Hicks, B. M., Iacono, W. G., \& McGue, M. (2014b). Childhood personality traits predict substance use disorders in adolescence and young adulthood: Comparing Big Three traits, socialization, and boldness. Submitted for publication.

Hicks, B. M., Johnson, W., Durbin, C. E., Blonigen, D. M., Iacono, W.G. \& McGue, M. (2013). Gene-environment correlation in the development of adolescent substance abuse: Selection effects of child personality and mediation of contextual risk factors. Development and Psychopathology, 25, 119-132.

Hicks, B. M., Krueger, R. F., Iacono, W. G., McGue, M., \& Patrick, C. J. (2004). Family transmission and heritability of externalizing disorders: A twin-family study. Archives of General Psychiatry, 61, 922-928.

Hill, J., Pickles, A., Rollinson, L., Davies, R., \& Byatt, M. (2004). Juvenile- versus adult-onset depression: Multiple differences imply different pathways. Psychological Medicine, 34, 1483-1493.

Hofmann, W., Baumeister, R. F., Förster, G., \& Vohs, K. D. (2012). Everyday temptations: An experience sampling study of desire, conflict, and self-control. Journal of Personality and Social Psychology, 102(6), 1318-1335.

Huang, C. (2010). Mean-level change in self-esteem from childhood through adulthood: Meta-analysis of longitudinal studies. Review of General Psychology, 14(3), 251-260.

Iacono, W. G., Carlson, S. R., Taylor, J., Elkins, I. J., \& McGue, M. (1999). Behavioral disinhibition and the development of substance use disorders: Findings from the Minnesota Twin Family Study. Development and Psychopathology, 11, 869-900.

Jaffee, S. R., Moffitt, T. E., Caspi, A., Fombonne, E., Poulton, R., \& Martin, J. (2002). Differences in early childhood risk factors for juvenile-onset and adult-onset depression. Archives of General Psychiatry, 58, 215-222.

Jahng, S., Solhan, M. B., Tomko, R. L., Wood, P. K., Piasecki, T. M., \& Trull, T. J. (2011). Affect and alcohol use: An ecological momentary assessment study of outpatients with borderline personality disorder. Journal of Abnormal Psychology, 120(3), 572-584.

Jessor, R., Donovan, J. E., \& Costa, F. M. (1991). Beyond adolescence: Problem behavior and young adult development. New York: Cambridge University Press.

John, O. P., \& Srivastava, S. (1990). The Big Five trait taxonomy: History, measurement, and theoretical perspectives. In L. A. Pervin, \& O. P. John (Eds.), Handbook of personality: Theory and research (2nd ed., pp. 102-138). New York: Guilford Press.

Johnson, W., Hicks, B. M., McGue, M., \& Iacono, W. G. (2007). Most of the girls are alright, but some aren't: Personality trajectory groups from ages 14 to 24 and some associations with outcomes. Journal of Personality and Social Psychology, 93, 266-284.

Johnston, L. D., O’Malley, P. M., \& Bachman, J. G. (1998). The development of heavy drinking and alcohol-related problems from ages 18 to 37 in the a U. S. national sample. Journal of Studies on Alcohol, 61, 290-300.

Johnstone, B. M., Leino, E. V., Ager, C. R., Ferrer, H., \& Fillmore, K. M. (1996). Determinants of life-course variation in the frequency of alcohol consumption: meta-analysis of studies from the Collaborative Alcohol-Related Longitudinal Project. Journal of Studies on Alcohol, 57, 494-506.
Kashdan, T. B., \& Steger, M. F. (2006). Expanding the topography of social anxiety: An experience-sampling assessment of positive emotions, positive events, and emotion suppression. Psychological Science, 17(2), 120-128.

Kendler, K. S., \& Gardner, C. O. (2010). Dependent stressful life events and prior depressive episodes in the prediction of major depression. Archives of General Psychiatry, 67(11), 1120-1127.

Kendler, K. S., Gatz, M., Gardner, C. O., \& Pedersen, N. L. (2006) Personality and major depression: A Swedish longitudinal, population-based twin study. Archives of General Psychiatry, 63, 1113-1120.

Kendler, K. S., Kuhn, J., \& Prescott, C. A. (2004). The interrelationship of neuroticism, sex, and stressful life events in the prediction of episodes of major depression. American Journal of Psychiatry, 161(4), 631-636.

Kendler, K. S., Neale, M. C., Kessler, R. C., Heath, A. C., \& Eaves, L. J. (1993). A longitudinal twin study of personality and major depression in women. Archives of General Psychiatry, 50, 853-862.

Kendler, K. S., Prescott, C. A., Myers, J., \& Neale, M. C. (2003). The structure of genetic and environmental risk factors for common psychiatric and substance use disorders in men and women. Archives of General Psychiatry, 60, 929-937.

Kessler, R. C., \& Wang, P. S. (2009). Epidemiology of depression. In I. H. Gotlib, \& C. L. Hammens (Eds.), Handbook of depression (2nd ed.). NY: Guilford. pp. 5-22.

Kessler, R. C., Berglund, P., Demler, O., Jin, R., Merikangas, K. R., \& Walters, E. E. (2005). Lifetime prevalence and age-of onset distributions of DSM-IV disorders in the National Comorbidity Survey Replication. Archives of General Psychiatry, 62, 593-602.

Keyes, K. M., Grant, B. F., \& Hasin, D. S. (2008). Evidence for a closing gender gap in alcohol use, abuse, and dependence in the United States population. Drug and Alcohol Dependence, 93, 21-29.

Klein, D. N. (2008). Classification of depressive disorders in DSMV: Proposal for a two-dimensional system. Journal of Abnormal Psychology, 117(3), 552-560.

Klein, D. N., Kotov, R., Bufferd, S. J., et al. (2011). Personality and depression: Explanatory models and review of the evidence. Annual Review of Clinical Psychology, 7, 269-295.

Klein, D. N., Schatzberg, A. F., McCullough, J. P., Dowling, F., Goodman, D., Howland, R. H., et al. (1999). Age of onset in chronic major depression: Relation to demographic and clinical variables, family history, and treatment response. Journal of Affective Disorders, 55, 149-157.

Klein, M. H., Wonderlich, S., \& Shea, M. T. (1993). Models of relationships between personality and depression: Toward framework for theory and research. In M. H. Klein, S. Wonderlich, \& M. T. Shea (Eds.), Personality and depression: A current view (pp. 1-54). NY: Guilford.

Kotov, R., Gamez, W., Schmidt, F., \& Watson, D. (2010). Linking "Big" personality traits to anxiety, depressive, and substance use disorders: A meta-analysis. Psychological Bulletin, 136, 768-821.

Krueger, R. F. (1999). The structure of common mental disorders. Archives of General Psychiatry, 56, 921-926.

Krueger, R. F., \& Tackett, J. L. (2003). Personality and psychopathology: Working toward the bigger picture. Journal of Personality Disorders, 17, 109-128.

Krueger, R. F., Caspi, A., Moffitt, T. E., Silva, P. A., \& McGee, R. (1996). Personality traits are differentially linked to mental disorders: A multitrait-multidiagnosis study of an adolescent birth cohort. Journal of Abnormal Psychology, 105, 299-312.

Krueger, R. F., Hicks, B. M., Patrick, C. J., Carlson, S. R., McGue, M., \& Iacono, W. G. (2002). Etiological relationships among substance dependence, antisocial behavior, and personality: Modeling the externalizing spectrum. Journal of Abnormal Psychology, 111, 411-424.

Krueger, R. F., Markon, K. E., Patrick, C. J., Benning, S. D., \& Kramer, M. D. (2007). Linking antisocial behavior, substance use, and personality: An integrative quantitative model of the adult externalizing spectrum. Journal of Abnormal Psychology, $116,645-666$. 
Krueger, R. F., McGue, M., \& Iacono, W. G. (2001). The higherorder structure of common DSM mental disorders: Internalization, externalization, and their connections to personality. Personality and Individual Differences, 30, 1244-1259.

Leggio, L., Kenna, G. A., Fenton, M., Bonefant, E., \& Swift, R. M. (2009). Typologies of alcohol dependence: From Jellinek to genetics and beyond. Neuropsychological Review, 19, 115-129.

Lehnart, J., Neyer, F. J., \& Eccles, J. (2010). Long-term effects of social investment: The case of partnering in young adulthood. Journal of Personality, 78(2), 639-669.

Lewinsohn, P. M., Clarke, G. N., Seeley, J. R., \& Rohde, P. (1994). Major depression in community adolescents: Age at onset, episode duration, and time to recurrence. Journal of the American Academy of Child and Adolescent Psychiatry, 33, 809-818.

Lewinsohn, P. M., Roberts, R. E., Seeley, J. R., Rohde, P., Gotlib, I. H., \& Hops, H. (1994). Adolescent psychopathology: II. Psychosocial risk factors for depression. Journal of Abnormal Psychology, 103, 302-315.

Littlefield, A. K., Sher, K. J., \& Steinley, D. (2010). Developmental trajectories of impulsivity and their association with alcohol use and related outcomes during emerging and young adulthood I. Alcoholism: Clinical and Experimental Research, 34, 1409-1416.

Littlefield, A. K., Sher, K. J., \& Wood, P. K. (2009). Is "maturing out" of problematic alcohol involvement related to personality change? Journal of Abnormal Psychology, 118, 360-374.

Littlefield, A. K., Sher, K. J., \& Wood, P. K. (2010). Do changes in drinking motives mediate the relation between personality change and the "maturing out" of alcohol problems? Journal of Abnormal Psychology, 119, 93-105.

Littlefield, A. K., Verges, A., Wood, P. K., \& Sher, K. J. (2012). Transactional models between personality and alcohol involvement: A further examination. Journal of Abnormal Psychology, 121, 778-783.

Lynn, R, \& Martin, T. (1997). Gender differences in extraversion, neuroticism, and psychoticism. Journal of Social Psychology, 137, 369-373.

Masten, A. S., Burt, K. B., Roisman, G. I., Obradovic, J., Long, J. D., \& Tellegen, A. (2004). Resources and resilience in the transition to adulthood: Continuity and change. Development and Psychopathology, 16, 1071-1094.

Masten, A. S., Coatsworth, J. D., Neemann, J., Gest, S. D., Tellegen, A., \& Garmezy, N. (1995). The structure and coherence of competence from childhood through adolescence. Child Development, 66, 1635-1659.

McAdams, D. P. (1985). Power, intimacy, and the life story: Personological inquiries into identity. NY: Guilford.

McAdams, D. P., \& Olson, B. D. (2010). Personality development: Continuity and change over the life course. Annual Review of Psychology, 61, 517-542.

McAdams, D. P., \& Pals, J. L. (2006). A new Big Five: Fundamental principles for an integrative science of psychology. American Psychologist, 61(3), 204-217.

McGue, M., Iacono, W. G., Legrand, L. N., Malone, S., \& Elkins, I. (2001). Origins and consequences of age at first drink. 1. Associations with substance-use disorders, disinhibitory behavior and psychopathology, and P3 amplitude. Alcoholism-Clinical and Experimental Research, 25, 1156-1165.

Mervielde, I., De Clerq, B., De Fruyt, F., \& Van Leeuwen, K. V. (2005). Temperament, personality, and developmental psychopathology as childhood antecedents of personality disorders. Journal of Personality Disorders, 19(2), 171-205.

Miller, G. A., \& Chapman, J. P. (2001). Misunderstanding analysis of covariance. Journal of Abnormal Psychology, 110, 40-48.

Mineka, S., Watson, D. W., \& Clark, L. A. (1998). Psychopathology: Comorbidity of anxiety and unipolar mood disorders. Annual Review of Psychology, 49, 377-412.

Molenaar, P. C. M., \& Campbell, C. G. (2009). The new personspecific paradigm in psychology. Current Direction in Psychological Science, 18(2), 112-117.
Neyer, F. J., \& Asendorpf, J. B. (2001). Personality-relationship transaction in young adulthood. Journal of Personality and Social Psychology, 81(6), 1190-1204.

Olino, T. M., Durbin, C. E., Klein, D. N., Hayden, E. P., \& Dyson, M. W. (2013). Gender differences in young children's temperament traits: Comparisons across observational and parent-report methods. Journal of Personality, 81(2), 119-129.

Ormel, J., Oldehinkel, A. J., \& Brilman, E. I. (2001). The interplay and etiological continuity of neuroticism, difficulties, and life events in the etiology of major and subsyndromal, first and recurrent depressive episodes in later life. American Journal of Psychiatry, 158(6), 885-891.

Ormel, J., Jeronimus, B. F., Kotov, R., Riese, H., Bos, E. H., Hankin, B., ... Oldehinkel, A. J. (2013). Neuroticism and common mental disorders: Meaning and utility of a complex relationship. Clinical Psychology Review, 33, 686-697.

Quilty, L. C., De Fruyt, F., Rolland, J.-P., Kennedy, S. H., Rouillon, P. F., \& Bagby, R. M. (2008). Dimensional personality traits and treatment outcome in patients with major depressive disorder. Journal of Affective Disorders, 108, 241-250.

Roberts, B. W., \& Caspi, A. (2003). The cumulative continuity principle of personality development: Striking a balance between continuity and change in personality traits across the lifecourse. In R. M. Staudinger, \& U. Lindenberger (Eds.), Understanding human development: Lifespan psychology in exchange with other disciplines (pp.183-214). Dordrecht, NL: Kluweer Academic Publishers.

Roberts, B. W., \& DelVecchio, W. F. (2000). The rank-order consistency of personality traits from childhood to old age: A quantitative review of longitudinal studies. Psychological Bulletin, 126, 3-25.

Roberts, B. W., Walton, K., Bogg, T., \& Caspi, A. (2006). De-investment in work and non-normative personality trait change in young adulthood. European Journal of Personality, 20, 461-474.

Roberts, B. W., Walton, K. E., \& Viechtbauer, W. (2006). Patterns of mean-level change in personality traits across the life course: A meta-analysis of longitudinal studies. Psychological Bulletin, $132,1-25$.

Roberts, B. W., \& Wood, D. (2006). Personality development in the context of the neo-socioanalytic model of personality. In D. K. Mroczek, \& T. D Little (Eds.), Handbook of personality development (pp. 11-39). Mahwah, NJ: Erlbaum.

Roberts, B. W., Caspi, A., \& Moffitt, T. (2001). The kids are alright: Growth and stability in personality development from adolescence to adulthood. Journal of Personality and Social Psychology, 81, 670-683.

Roberts, R. W., Wood, D., \& Smith, J. L. (2005). Evaluating Five-Factor theory and social investment perspectives on personality trait development. Journal of Research in Personality, 39, 166-184.

Rohde, P., Lewinsohn, P. M., Klein, D. N., Seeley, J. R., \& Gau, J. M. (2013). Key characteristics of major depressive disorder occurring in childhood, adolescence, emerging adulthood, and adulthood. Clinical Psychological Science, 1, 41-53.

Roisman, G. I., Masten, A. S., Coatsworth, J. D., \& Tellegen, A. (2004). Salient and emerging developmental tasks in the transition to adulthood. Child Development, 75, 123-133.

Schulenberg, J., O'Malley, P. M., Bachman, J. G., Wadsworth, K. N., \& Johnston, L. D. (1996). Getting drunk and growing up: Trajectories of frequent binge drinking during the transition to young adulthood. Journal of Studies on Alcohol, 57, 289-304.

Sher, K. J., Jackson, K. M., \& Steinley, D. (2011). Alcohol use trajectories and the ubiquitous cat's cradle: Cause for concern? Journal of Abnormal Psychology, 120, 322-335.

Simons, R. G., Burgeson, R., \& Carlton-Ford, S. (1987). The impact of cumulative change in early adolescence. Child Development, $58,1220-1234$.

Slutske, W. S., Heath, A. C., Madden, P. A. F., Bucholz, K. K., Statham, D. J., \& Martin, N. G. (2002). Personality and the genetic risk for alcohol dependence. Journal of Abnormal Psychology, 111, 124-133. 
Soto, C. J., John, O. P., Gosling, S. D., \& Potter, J. (2011). Age differences in personality trait from 10 to 65: Big Five domains and facets in a large cross-sectional sample. Journal of Personality and Social Psychology, 100, 330-348.

Specht, J., Egloff, B., \& Schmukle, S. C. (2011). Stability and change in personality across the life course: The impact of age and major life events on mean-level and rank-order stability of the Big Five. Journal of Personality and Social Psychology, 101(4), 862-882.

Steinberg, L. (2008). A social neuroscience perspective on adolescent risk-taking. Developmental Review, 28(1), 78-106.

Stroud, C. B., Davila, J., Hammen, C., \& Vrshek-Schallhorn, S. (2010). Severe and nonsevere events in first onsets versus recurrences of depression: Evidence for stress generation. Journal of Abnormal Psychology, 120(1), 142-154.

Tackett, J. L., Krueger, R. F., Iacono, W. G., \& McGue, M. (2008). Personality in middle childhood: A hierarchical structure and longitudinal connections with personality in late adolescence. Journal of Research in Personality, 42, 1456-1462.

Tang, T. Z., DeRubeis, R. J., Hollon, S. D., Amsterdam, J., Shelton, R., \& Schalet, B. (2009). Personality change during depression treatment. Archives of General Psychiatry, 66, 1322-1330.

Tellegen, A. (1985). Structures of mood and personality and their relevance to assessing anxiety, with an emphasis on self-report. In A. H. Tuma, \& J. D. Maser (Eds.), Anxiety and the anxiety disorders (pp. 681-706). Hillsdale, NJ: Erlbaum.

Tellegen, A., \& Waller, N. G. (2008). Exploring personality through test construction: Development of the Multidimensional Personality Questionnaire. In G. J. Boyle, G. Matthews, \& D. H. Saklofske (Eds.), The Sage handbook of personality theory and assessment: Vol. II. Personality measurement and testing (pp. 261-292). London: Sage.

Uliaszek, A. A., Zinbarg, R. E., Mineka, S., Craske, M. G., Griffith, J. W., et al. (2012). A longitudinal examination of stress generation in depressive and anxiety disorders. Journal of Abnormal Psychology, 121(1), 4-15.
Van Os, J., \& Jones, P. B. (1999). Early risk factors and adult person-environment relationships in affective disorder. Psychological Medicine, 29, 1055-1067.

Verges, A., Jackson, K. M., Bucholz, K. K., Grant, J. D., Trull, T. J., Wood, P. K., \& Sher, K. J. (2012). Deconstructing the ageprevalence curve of alcohol dependence: Why "maturing out" is only a small piece of the puzzle. Journal of Abnormal Psychology, 121, 511-523.

Vollebergh, W. A. M., Iedema, J., Bijl, R. V., de Graaf, R., Smit, F., \& Ormel, J. (2001). The structure and stability of common mental disorders. Archives of General Psychiatry, 58, 597-603.

Watson, D., \& Clark, L. A. (1995). Depression and the melancholic temperament. European Journal of Personality, 9, 351-366.

Wichers, M. C., Myin-Germeys, I., Jacobs, N., Peeters, F., Kenis, G., Derom, C., ... van Os, J. (2007). Evidence that moment-tomoment variation in positive emotions buffer genetic risk for depression: A momentary assessment twin study. Acta Psychiatrica Scandinavica, 115, 451-457.

Wilson, S., Hicks, B. M., Foster, K. T., Iacono, W. G., \& McGue, M. (in press). Age of onset and recurrence of major depressive disorder: Associations with psychosocial functioning in adolescence and adulthood. Psychological Medicine, Under review.

Winick, C. (1962). Maturing out of narcotic addiction. Bulletin on Narcotics, 14, 1-7.

Yamaguchi, K., \& Kandel, D. (1985). On the resolution of role incompatibility: Life event history analysis of family roles and marijuana use. American Journal of Sociology, 90, 1284-1325.

Zeiss, A. M., \& Lewinsohn, P. M. (1988). Enduring deficits after remissions of depression: A test of the scar hypothesis. Behaviour Research and Therapy, 26, 151-158.

Zisook, S., Lesser, I., Stewart, J. W., Wisniewski, S. R., Balasubramani, G. K., Fava, M., et al. (2007). Effect of age at onset on the course of major depressive disorder. American Journal of Psychiatry, 164, 1539-1546. 